\title{
Nucleation and Growth Process of Sodalite and Cancrinite from Kaolinite-rich Clay under Low-temperature Hydrothermal Conditions
}

\author{
Carlos Alberto Ríos Reyes ${ }^{\text {a* }}$, Craig Williams ${ }^{\mathrm{b}}$, Oscar Mauricio Castellanos Alarcón ${ }^{\mathrm{c}}$ \\ ${ }^{a}$ Escuela de Geología, Universidad Industrial de Santander, Carrera 27 Calle 9 , \\ Ciudad Universitaria, Bucaramanga, Colombia \\ ${ }^{\mathrm{b}}$ School of Applied Sciences, University of Wolverhampton, Wulfruna Street, \\ Wolverhampton WV1 1SB, England \\ 'Programa de Geología, Universidad de Pamplona, Ciudad Universitaria, Pamplona, Colombia
}

Received: October 28, 2011; Revised: August 24, 2012

\begin{abstract}
The synthesis of low-silica zeotypes by hydrothermal transformation of kaolinite-rich clay and the nucleation and growth processes of sodalite and cancrinite in the system $\mathrm{Na}_{2} \mathrm{O}-\mathrm{Al}_{2} \mathrm{O}_{3}-\mathrm{SiO}_{2}-\mathrm{H}_{2} \mathrm{O}$ at $100{ }^{\circ} \mathrm{C}$ were investigated. The synthesis products were characterized by X-ray powder diffraction (XRPD), scanning electron microscopy (SEM), Fourier transform infrared spectroscopy (FT-IR), ${ }^{29} \mathrm{Si}$ and ${ }^{27}$ Al Magic Angle Spinning Nuclear Magnetic Resonance (MAS-NMR) and thermogravimetric analysis (TGA). Our data show that the sequence of the transformation of phases is: Poorly crystalline aluminosilicate $\rightarrow$ zeolite LTA $\rightarrow$ sodalite $\rightarrow$ sodalite + cancrinite $\rightarrow$ cancrinite. Synthesized materials appeared stable thermodynamically under the experimental conditions, with zeolite LTA (a metastable phase) occurring as a minor phase, compared with the presence of sodalite and cancrinite.
\end{abstract}

Keywords: synthesis, low-silica, hydrothermal, kaolinite, transformation

\section{Introduction}

The Bayer process is the principal industrial means of refining bauxite to produce alumina $\left(\mathrm{Al}_{2} \mathrm{O}_{3}\right)$, which must be purified before it can be refined to aluminium metal. During alumina production, bauxite is digested by washing with a hot solution of sodium hydroxide $(\mathrm{NaOH})$ at elevated temperatures ${ }^{1}$. $\mathrm{SiO}_{2}$, an impurity in the bauxite in the form of kaolinite and quartz, can also be digested. After digestion, the dissolved $\mathrm{SiO}_{2}$, subsequently reacts with the ionic species in the sodium aluminate solution to form a "desilication product" (commonly known as DSP) which primarily consists sodium aluminosilicates, such as sodalite (SOD) and cancrinite $(\mathrm{CAN})^{1-4}$. Both SOD and CAN are of the common chemical formula $\mathrm{Na}_{6}\left[\mathrm{Al}_{6} \mathrm{Si}_{6} \mathrm{O}_{24}\right] \cdot 2 \mathrm{NaX} \cdot 6 \mathrm{H}_{2} \mathrm{O}$, where $\mathrm{X}$ can be $\mathrm{OH}^{-}, \mathrm{Cl}^{-}, \mathrm{NO}_{3}^{-}, 1 / 2 \mathrm{CO}_{3}{ }^{2-}$, or $1 / 2 \mathrm{SO}_{4}{ }^{2-}$.

However, their structural frameworks are different (Figure 1). SOD has a cubic framework that contains only $\beta$-cages made up of eight 6 -membered rings of alternating $\mathrm{AlO}_{4}$ and $\mathrm{SiO}_{4}$ tetrahedra and six 4-membered rings; the free dimension of the inscribed sphere of the $\beta$-cage is $6.6 \AA$ and access to the cage through the 6-membered ring window (channel) is $\sim 2.2 \AA^{[3]}$. CAN has a hexagonal framework that contains small $\varepsilon$-cages consisting of five 6-membered rings and six 4-membered rings, which give rise to large continuous channels consisting of 12-membered rings with a free dimension of $\sim 6.2 \AA^{[5]}$. In general, these aluminosilicates are characterized by a three-dimensional framework, which contain cages and channels in their negatively charged frameworks because of the substitution of $\mathrm{Si}^{4+}$ ions by $\mathrm{Al}^{3+}$ ions ${ }^{6}$. Both the $\beta$ - and $\varepsilon$ - cages need

*e-mail: carios@uis.edu.co positively charged species to neutralise them ${ }^{3}$. Cations can enter these porous materials to balance the charge of their structural frameworks ${ }^{6}$. Structural data of these zeolite frameworks are published by the 'Structure Commission of the International Zeolite Association' (IZA) ${ }^{7}$.

The low-temperature hydrothermal conversion of kaolinite and metakaolinite to low silica zeolites (LSZs) is a very well known process, with zeolite LTA as the most common synthesis product ${ }^{8}$, which is a metastable phase during the formation of SOD and CAN. The synthesis of zeolites from kaolinite has been extensively investigated ${ }^{5,9}$. However, the improvement of the kaolinite properties by chemical methods is difficult due to its low reactivity; this clay mineral is not significantly affected by acid or alkaline treatments, even under strong conditions ${ }^{10}$. Therefore, kaolinite is usually used after calcination at temperatures between $550-950{ }^{\circ} \mathrm{C}^{11}$ to obtain a more reactive phase (metakaolinite) under chemical treatments. Several authors have reported the synthesis of metakaolinite-based zeolitic materials, including the zeolite LTA ${ }^{8,12-15}$. The mechanisms and kinetics of SOD and CAN formation have been investigated by several authors ${ }^{1-3,16}$. According to Barnes et al. ${ }^{2}$, the phase transformation from SOD to CAN was a solution-mediated process, which involved a fourstage mechanism. However, there are many inconsistencies in the published sodium aluminosilicate equilibrium solubility data particularly for the SOD and CAN phases ${ }^{17}$. On the other hand, whether or not the crystalline phase underwent any transformation changes (e.g. SOD to CAN) was either not determined or not taken into account ${ }^{18}$. 


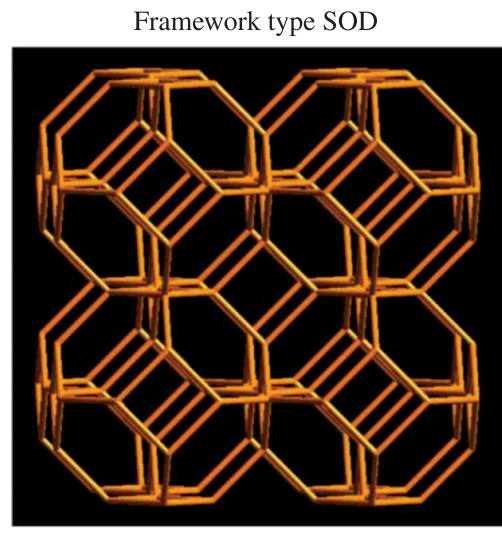

Viewed along [001]

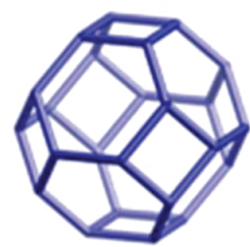

SOD cage

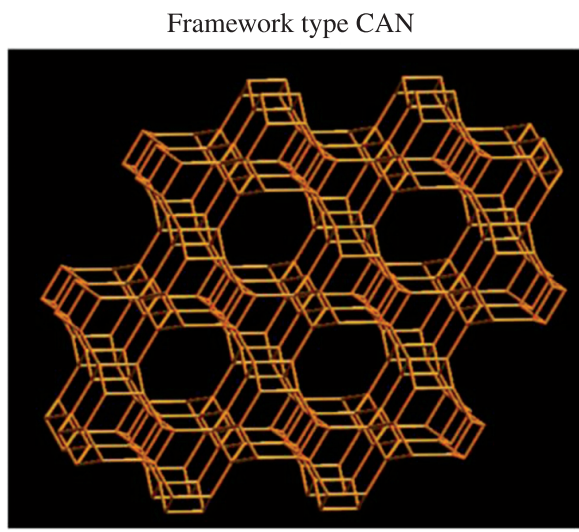

Viewed along [001]

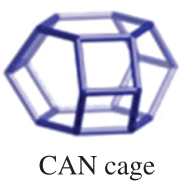

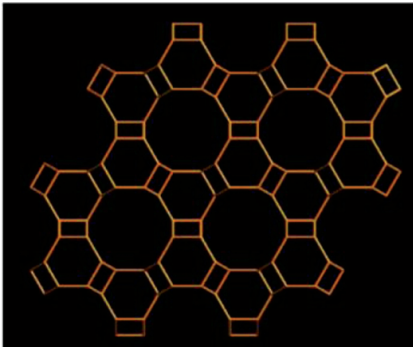

Projection viewed along [001]

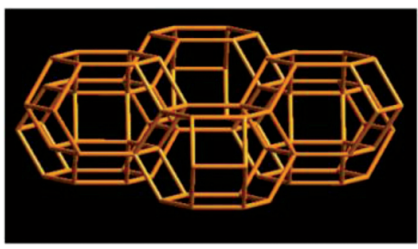

Array of CAN cages viewed normal to [001]

Figure 1. Framework structures of SOD and CAN, showing their characteristic cages and channels, adopted and modified from the Database of Zeolite Structures ${ }^{7}$.

In this work, we investigate not only the low-temperature hydrothermal transformation of kaolinite and metakaolinite into SOD and CAN-type structures but also the phase transformation from SOD to CAN. On the other hand, this research is also useful in order to understand the common natural process of low to medium temperature alteration of feldespatoids in alkaline volcanic and subvolcanic rocks.

\section{Experimental}

\subsection{Material}

The raw material used in this study was a kaoliniterich clay (distributed under the name Supreme Powder and supplied by English China Clay International). Metakaolinite was obtained by thermal treatment at $600{ }^{\circ} \mathrm{C}$ of the kaolinite-rich clay. Both kaolinite and metakaolinite were used as starting materials for the synthesis of zeotypes. Other reagents used in the activation of the raw materials were: sodium hydroxide, $\mathrm{NaOH}$, as pellets $(99.99 \%$, Aldrich Chemical Company, Inc.) and distilled water using standard purification methods.

\subsection{Synthesis of SOD- and CAN-type structures}

Zeotype synthesis was carried out under hydrothermal conditions in alkaline medium using kaolinite and metakaolinite as silica and alumina sources. A calculated amount of alkali hydroxide pellets was added to distilled water in reaction plastic beakers $(150-250 \mathrm{~mL})$ to prepare $1.33 \mathrm{M}$ and $3.99 \mathrm{M} \mathrm{NaOH}$ solutions; the starting materials were then mixed with the alkaline solutions to produce a reaction gel with a specific molar composition. The progressive addition of reagents was carried out under stirring conditions until they dissolved to homogenize the reaction gels. Crystallization was carried out by hydrothermal synthesis under static conditions in PTFE vessels of $65 \mathrm{~mL}$ at $100{ }^{\circ} \mathrm{C}$ for several reaction times. Once the activation time was reached, the reactors were removed from the oven and quenched in cold water to stop the reaction. After hydrothermal treatment, the reaction mixtures were filtered and washed with distilled water to remove excess alkali until the $\mathrm{pH}$ of the filtrate became neutral. Then, the samples were oven dried at $80{ }^{\circ} \mathrm{C}$ overnight. The hydrogel $\mathrm{pH}$ was measured before and after hydrothermal treatment. The dried samples were weighted and kept in plastic bags for characterization. Table 1 presents the experimental conditions used for zeolite synthesis.

\subsection{Characterization of the starting materials and as-synthesized zeotypes}

$\mathrm{X}$-ray diffraction (XRD) patterns of the starting materials and as-synthesized zeotypes were recorded using a Philips PW1710 diffractometer operating in Bragg-Brentano geometry with $\mathrm{Cu}-\mathrm{K} \alpha$ radiation $(40 \mathrm{kV}$ and $40 \mathrm{~mA}$ ) and secondary monochromation. Data collection was carried out in the $2 \theta$ range $3-50^{\circ}$, with a step size of $0.02^{\circ}$, a divergent slit of $1.0^{\circ}$, and a dwell time of 2 seconds Phase identification was performed by searching the ICDD powder diffraction file database, with the help of JCPDS files for inorganic compounds. The morphology of the solid phases were 
examined in a ZEISS EVO50 scanning electron microscopy (SEM) under the following analytical conditions: I probe $1 \mathrm{nA}, \mathrm{EHT}=20.00 \mathrm{kV}$, beam current $100 \mu \mathrm{A}$, Signal A = SE1, $\mathrm{WD}=8.0 \mathrm{~mm}$. Specimens were prepared by spraying dried raw material or zeolite powder onto aluminium stubs using double-sided adhesive carbon discs and sputter coated with gold to reduce static charging and then observing under SEM conditions. For EDX analysis the samples were prepared in a similar way to SEM. However, to avoid errors in the aluminium content, a carbon sample holder was used instead of aluminium stud and gold was not coated on the samples. Fourier transform infrared (FT-IR) spectroscopy was performed using a Mattson Genesis II FT-IR spectrometer in the $4000-400 \mathrm{~cm}^{-1}$ region. However, only the $1200-400 \mathrm{~cm}^{-1}$ region was investigated, taking into account that it is where the spectra showed remarkable changes. Solid-state ${ }^{29} \mathrm{Si}$ and ${ }^{27}$ Al Magic Angle Spinning Nuclear Magnetic Resonance (MAS NMR) spectra were recorded on a Varian UnityInova spectrometer under the following analytical conditions: MAS probe 7.5-4.0 mm; frequency 59.6-78.1 MHz; spectral width 29996-100000 Hz; acquisition time $30-10 \mathrm{~ms}$; recycle time 120-0.5 seconds; number of repetitions 15-2200; spinning rate $5040-14000 \mathrm{~Hz}$; pulse angle $\pi / 2-\pi / 10$. The chemical shifts were referenced to tetramethylsilane (TMS) for ${ }^{29} \mathrm{Si}$ and $1 \mathrm{MAlCl} 3$ aqueous solution for ${ }^{27} \mathrm{Al}$. Thermogravimetric analyses (TGA) were performed on a Mettler Toledo TG 50 thermobalance between $25-700{ }^{\circ} \mathrm{C}$ at a heating rate of $20{ }^{\circ} \mathrm{C} / \mathrm{min}$ under flowing air $\left(200 \mathrm{~cm}^{3} / \mathrm{min}\right)$. The ground sample was directly filled into the crucible for testing. The amount was normally $\sim 15-20 \mathrm{mg}$ to minimize background noise.

\section{Results and Discussion}

\subsection{Starting materials}

The XRD patterns of the starting materials are presented in Figure 2. Kaolinite (Figure 2a) in the sample is identified by its characteristic XRD peaks at $12.34^{\circ}$ and $24.64^{\circ}$ $2 \theta$. However, minor impurities, such as illite, muscovite and halloysite, also occur. Metakaolinite (Figure 2b) is characterized by the disappearance of all the XRD peaks of kaolinite, accompanied by the appearance of an amorphous aluminosilicate (see the broad hump at $2 \theta=13-33^{\circ}$, having a maximum at $2 \theta=\sim 22^{\circ}$ ). Similar results have been observed by as reported in several studies ${ }^{19-21}$.

Table 1. Synthesis conditions for transformation of kaolinite and metakaolinite into SOD and CAN zeotypes.

\begin{tabular}{|c|c|c|c|c|c|c|c|}
\hline \multicolumn{4}{|c|}{ Chemical reagents } & \multirow{2}{*}{$\begin{array}{c}\text { L/S ratio } \\
(\mathrm{mL} / \mathrm{g}) \\
\end{array}$} & \multicolumn{2}{|c|}{ Hydrothermal treatment } & \multirow{2}{*}{$\begin{array}{l}\text { Molar gel } \\
\text { composition }\end{array}$} \\
\hline $\mathrm{H}_{2} \mathrm{O}(\mathrm{mL})$ & $\mathrm{NaOH}(g)$ & $\mathbf{K A O}(\mathbf{g})$ & $\operatorname{MTK}(\mathrm{g})$ & & $\mathbf{T}\left({ }^{\circ} \mathbf{C}\right)$ & t (hours) & \\
\hline 18.00 & 0.96 & 3.10 & & 6.12 & 100 & 6 & $\mathrm{Na}_{2} \mathrm{O}: \mathrm{Al}_{2} \mathrm{O}_{3}: 2 \mathrm{SiO}_{2}: 86.3 \mathrm{H}_{2} \mathrm{O}$ \\
\hline 18.00 & 0.96 & 3.10 & & 6.12 & 100 & 72 & $\mathrm{Na}_{2} \mathrm{O}: \mathrm{Al}_{2} \mathrm{O}_{3}: 2 \mathrm{SiO}_{2}: 86.3 \mathrm{H}_{2} \mathrm{O}$ \\
\hline 18.00 & 0.96 & 3.10 & & 6.12 & 100 & 120 & $\mathrm{Na}_{2} \mathrm{O}: \mathrm{Al}_{2} \mathrm{O}_{3}: 2 \mathrm{SiO}_{2}: 86.3 \mathrm{H}_{2} \mathrm{O}$ \\
\hline 18.00 & 2.87 & 3.10 & & 6.73 & 100 & 6 & $3 \mathrm{Na}_{2} \mathrm{O}: \mathrm{Al}_{2} \mathrm{O}_{3}: 2 \mathrm{SiO}_{2}: 88.3 \mathrm{H}_{2} \mathrm{O}$ \\
\hline 18.00 & 2.87 & 3.10 & & 6.73 & 100 & 72 & $3 \mathrm{Na}_{2} \mathrm{O}: \mathrm{Al}_{2} \mathrm{O}_{3}: 2 \mathrm{SiO}_{2}: 88.3 \mathrm{H}_{2} \mathrm{O}$ \\
\hline 18.00 & 2.87 & 3.10 & & 6.73 & 100 & 120 & $3 \mathrm{Na}_{2} \mathrm{O}: \mathrm{Al}_{2} \mathrm{O}_{3}: 2 \mathrm{SiO}_{2}: 88.3 \mathrm{H}_{2} \mathrm{O}$ \\
\hline 18.00 & 0.96 & & 2.67 & 7.10 & 100 & 22 & $\mathrm{Na}_{2} \mathrm{O}: \mathrm{Al}_{2} \mathrm{O}_{3}: 2 \mathrm{SiO}_{2}: 84.2 \mathrm{H}_{2} \mathrm{O}$ \\
\hline 18.00 & 0.96 & & 2.67 & 7.10 & 100 & 28 & $\mathrm{Na}_{2} \mathrm{O}: \mathrm{Al}_{2} \mathrm{O}_{3}: 2 \mathrm{SiO}_{2}: 84.2 \mathrm{H}_{2} \mathrm{O}$ \\
\hline 18.00 & 0.96 & & 2.67 & 7.10 & 100 & 52 & $\mathrm{Na}_{2} \mathrm{O}: \mathrm{Al}_{2} \mathrm{O}_{3}: 2 \mathrm{SiO}_{2}: 84.2 \mathrm{H}_{2} \mathrm{O}$ \\
\hline
\end{tabular}

KAO, kaolinite; MTK, metakaolinite; L/S, alkaline solution/raw material ratio.

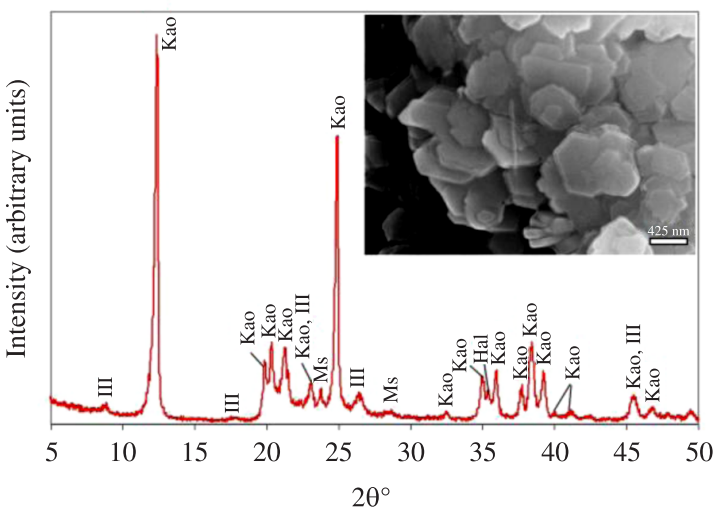

(a)

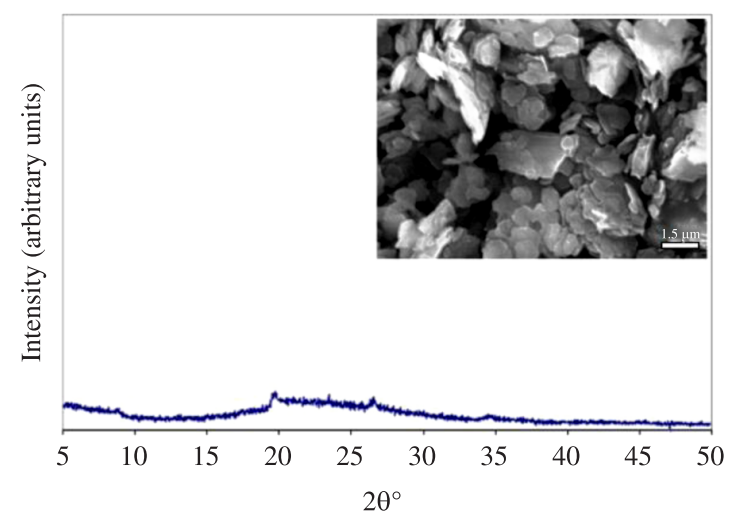

(b)

Figure 2. X-ray diffraction patterns and SEM images of the starting materials (a) kaolinite and (b) metakaolinite. Kao, Kaolinite; Ili, illite; Ms, muscovite; Hal, halloysite. 
The SEM micrographs (Figure 2) reveals that kaolinite (Figure 2a) displays a platy morphology and hexagonal outlines, with small, well-formed hexagonal plates loosely packed, defining an orientation, whereas metakaolinite (Figure 2b) occurs as a mixture of large plates and stacks.

The FT-IR spectra of the starting materials (Figure 3) resemble those reported in previous studies. The vibration bands of kaolinite are described as follows. The band at $1119 \mathrm{~cm}^{-1}$ is referred to $\mathrm{Si}-\mathrm{O}$ stretching vibrations, while the bands at 1034 and $1012 \mathrm{~cm}^{-1}$ are rather caused by Si-O-Si and $\mathrm{Si}-\mathrm{O}-\mathrm{Al}$ lattice vibrations ${ }^{22}$. The $\mathrm{OH}$ bending vibrations at 942 and $916 \mathrm{~cm}^{-1}$ can be referred to the surface $\mathrm{OH}$ bending' and 'inner $\mathrm{OH}$ bending' ${ }^{23}$, which are mainly caused by $\mathrm{Al}-\mathrm{OH}$ groups ${ }^{22}$. Further, bands in low range of frequency (762, 696 and $539 \mathrm{~cm}^{-1}$ ) can be attributed to different $\mathrm{Si}-\mathrm{O}$ and Al-O vibrations ${ }^{24}$. The conversion of kaolinite to metakaolinite is revealed by the disappearance of these characteristic bands, similar to what is reported in previous studies ${ }^{19-20}$. The vibration bands observed in metakaolinite were $1049,806,642,571$ and $428 \mathrm{~cm}^{-1}$, with three broad bands centred at 1049, 806 and $428 \mathrm{~cm}^{-1}$. A significant shift of the Si-O vibration bands at 1034 and $1012 \mathrm{~cm}^{-1}$ in kaolinite to a higher frequency band at $1049 \mathrm{~cm}^{-1}$ was observed, which has been assigned to amorphous $\mathrm{SiO}_{2}{ }^{[25]}$. The stretching vibration of $\mathrm{Al}(\mathrm{O}, \mathrm{OH})_{6}$ octahedra in kaolinite ${ }^{26}$ is observed at $539 \mathrm{~cm}^{-1}$, but is substituted by a peak at $806 \mathrm{~cm}^{-1}$ corresponding to the vibration band of $\mathrm{AlO}_{4}$ tetrahedron in metakaolinite.

The ${ }^{29} \mathrm{Si}$ MAS-NMR spectra of kaolinite and metakaolinite are given in Figure 4. The ${ }^{29} \mathrm{Si}$ MAS-NMR spectrum of kaolinite (Figure 4a) displays two well resolved signals at -90.9 and $-91.4 \mathrm{ppm}$ attributed to the existence of two different but equally populated silicon sites. Similar results have been reported in several studies ${ }^{27,28}$. According to Thompson and Barron $1^{27}$, the interlayer hydrogen bonding resulting in two different silicon environments is the main reason for the ${ }^{29} \mathrm{Si}$ MAS-NMR signal splitting in kaolinite. The ${ }^{29} \mathrm{Si}$ MAS-NMR spectrum of metakaolinite (Figure 4b) displays a broad signal around $-96.3 \mathrm{ppm}$, indicating its heterogeneity, with Si linked to four other $\mathrm{Si}$ atoms in silica polymorphs ${ }^{29}$ and the presence of amorphous silica ${ }^{30}$. According to Mackenzie et al. ${ }^{31}$, when kaolinite is dehydroxylated, the $\mathrm{Si}$ atoms undergo a range of environments of different distortion and the broadness of the metakaolinite line is attributed to these variations in the $\mathrm{Si}-\mathrm{O}-\mathrm{Si}(\mathrm{Al})$ bond angles. The ${ }^{27} \mathrm{Al}$ MAS-NMR spectrum of kaolinite (Figure 4a) consists of a sharp octahedral Al-O resonance at $-3.4 \mathrm{ppm}$ attributed to 6-coordinated Al. The ${ }^{27} \mathrm{Al}$ MAS-NMR spectrum of metakaolinite (Figure $4 \mathrm{~b}$ ) contains broad overlapping resonances at $-0.3,23.4$ and 45.9 ppm that can be attributed to 6-, 5- and 4-coordinated Al local environments, in agreement with data reported by Rocha ${ }^{32}$, although different compared with those reported by several authors ${ }^{30,33}$. This reveals that the dehydroxylation of kaolinite brings about major changes, especially in the octahedral Al-O layers which are most closely associated with the structural hydroxyl groups ${ }^{31}$. The broader and asymmetrical peak shapes of metakaolinite show its disordered structure ${ }^{33}$. However, it is very complicate to speculate on the metakaolinite structure, taking into account that there are a number of transitional stages, $\mathrm{f}, \mathrm{i}$, related to the temperature and duration of the kaolinite structure breakdown.

The thermal decomposition of kaolinite is illustrated in the TG and its first derivative (DTG) curves on Figure 5. At $<100^{\circ} \mathrm{C}$, low temperature release of absorbed water occurs.

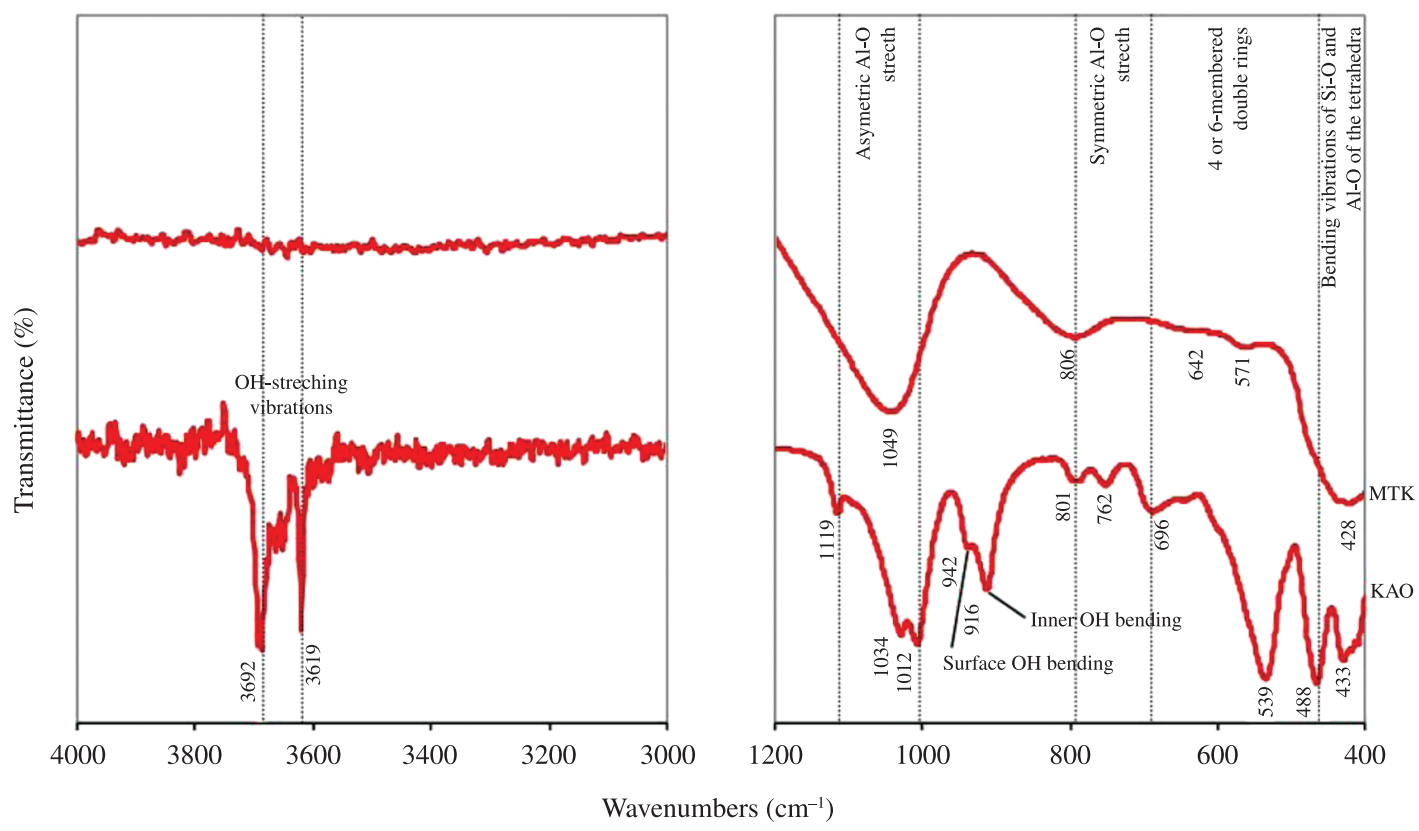

Figure 3. FTIR spectra of the starting materials. KAO, kaolinite; MTK, metakaolinite. 


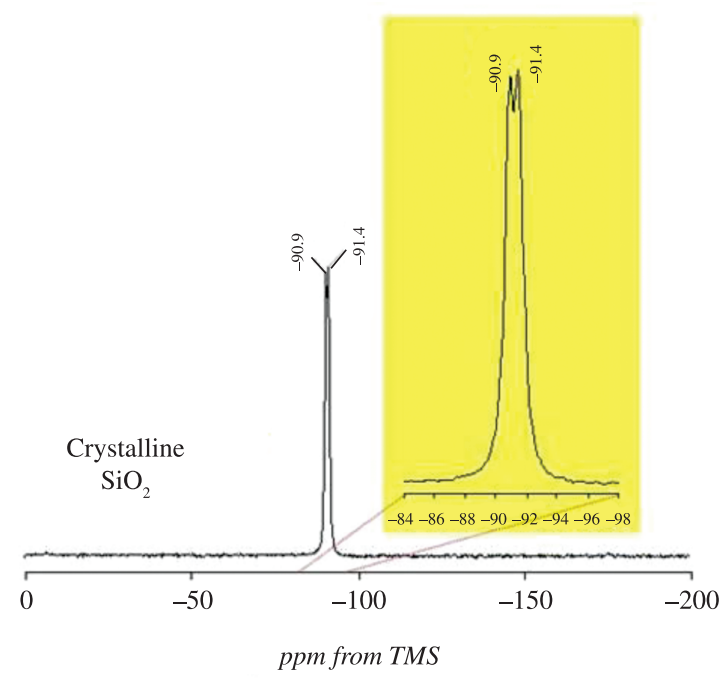

${ }^{29} \mathrm{Si}$

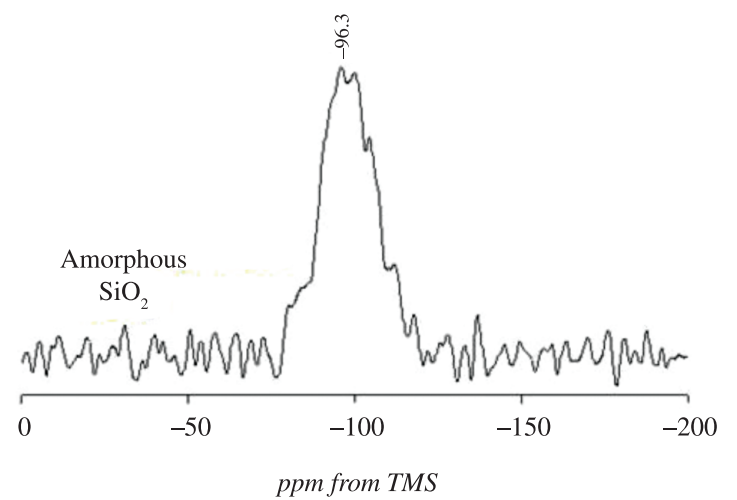

${ }^{29} \mathrm{Si}$

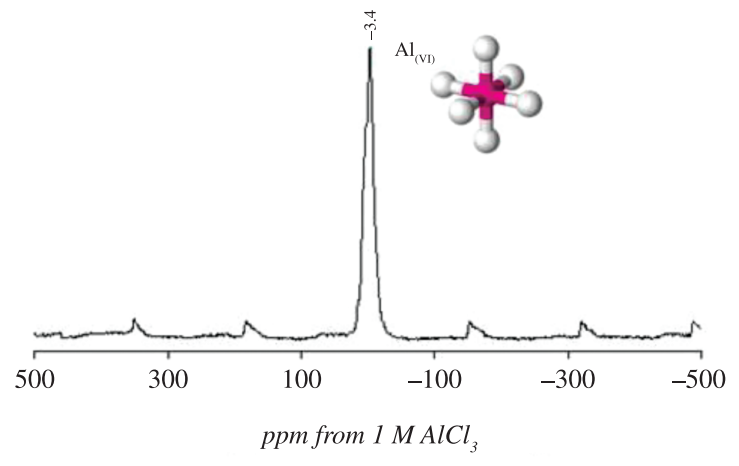

${ }^{27} \mathrm{Al}$

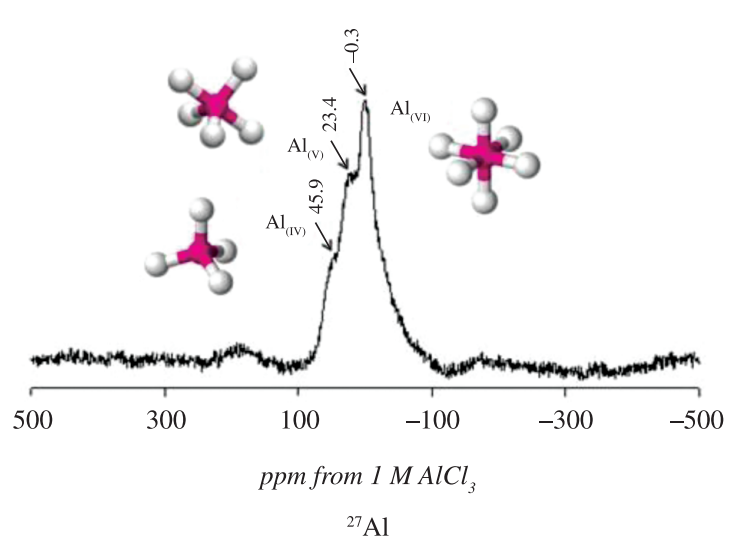

(b)

Figure 4. Soli-state ${ }^{29} \mathrm{Si}$ and ${ }^{27} \mathrm{Al}$ MAS-NMR spectra of the starting materials: (a) kaolinite and (b) metakaolinite.

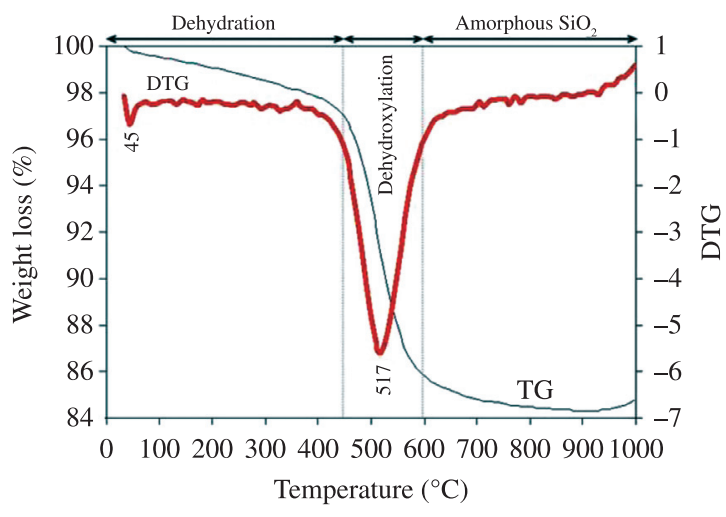

Figure 5. TG/DTG curves between $25-1000{ }^{\circ} \mathrm{C}$ for kaolinite.

Between $\sim 100-450{ }^{\circ} \mathrm{C}$, a pre-dehydration process takes place as a result of the reorganization in the octahedral layer, first occurring at the $\mathrm{OH}$ of the surface ${ }^{34}$. After dehydration, kaolinite undergoes a pre-dehydroxylation state ${ }^{35}$. Between $\sim 450-600{ }^{\circ} \mathrm{C}$, the kaolinite dehydroxylation occurs, with the transformation to a non-crystalline phase, metakaolinite. According to Varga ${ }^{36}$, the transformation of kaolinite into metakaolinite by dehydroxylation results in structural disturbances through the breaking of unstable bonds. As a result, the degree of ordering became lower than that in kaolinite as dehydroxylation progressed. The structure of metakaolinite does not collapse but, rather, retains a layered structure. A progressive decomposition of the metakaolinite occurs up to $900{ }^{\circ} \mathrm{C}$. An exothermic peak at $\sim 1000{ }^{\circ} \mathrm{C}$ reveals the breakdown of the metakaolinite structure and the formation of mullite or Si-Al spinel with mullite-like composition, as reported by Chakravorty and $\mathrm{Ghosh}^{37}$.

\subsection{As-synthesized zeotypes}

\subsubsection{XRD analysis}

As mentioned before, the structural frameworks of both SOD and CAN are similar. As a result many diffraction peaks 
occur at the same d-spacings for the two phases. The main identifying peaks for CAN are the 101 and 211 occurring at $\mathrm{d} \sim 4.67$ and $3.24 \AA$, respectively, which are not found in a SOD diffraction pattern ${ }^{1}$. The XRD patterns of the untreated starting materials and the as-synthesized products obtained after hydrothermal treatment under alkaline conditions are presented in Figure 6. The hydrothermal treatment of kaolinite (Figure 6a) and metakaolinite (Figure 6b) under these experimental conditions resulted in the cocrystallization of SOD and CAN, along with metastable zeolite LTA. Therefore, a mix of new phases (SOD and CAN), with zeolite LTA, in the synthesis products, is observed. A higher reaction time promotes a more effective dissolution of the starting materials, accompanied by more crystalline zeotypes, as shown by an increase of the relative intensity of the XRD peaks of SOD and CAN. In general, a decrease in the kaolinite relative intensity suggests that the formation of zeolite LTA, CAN and SOD enhanced the dissolution of kaolinite by removing $\mathrm{Al}$ from solution, whereas the transformation of the amorphous character of the metakaolinite to crystalline phases is revealed as well.

\subsubsection{SEM analysis}

A SEM study was carried out to provide information about the particle morphology and crystal growth process. SEM images (Figures 7-8) illustrate the occurrence of the as-synthesized zeotypes obtained after activation of the starting materials, revealing a change in morphology of the original surface of the particles of the starting materials. We highlight more examples of the zeotypes obtained using kaolinite as a starting material, taking into account that the synthesis products reveal the occurrence of SOD and CAN along with traces of zeolite LTA, which as the reaction proceeds display a metastable behaviour. On the other hand, an almost pure zeolite A (with minor SOD and CAN) was obtained after transformation of metakaolinite.

Using kaolinite as a starting material, the following morphologies were observed in the as-synthesized zeotypes. Well developed crystals of zeolite LTA displaying a cubic morphology and interpenetration-twinning are observed in Figure $7 \mathrm{a}$-d. Note the spherical aggregates of SOD growing out onto the surface of zeolite LTA as reported by Ríos and co-workers ${ }^{6,14,15}$, revealing that SOD can be the result of secondary nucleation as reported previously ${ }^{38}$ and not the result of direct solid-state transformation. As shown in Figure 7e, fCAN occurs as lepispheres composed of intergrown thin disks that grew at the expenses of SOD (a wedge-shaped blade morphology). The phase transformation SOD $\rightarrow$ CAN has been reported by Barnes and co-workers ${ }^{1-2,4}$. According to Deng et al. ${ }^{39}$, CAN occurs as more tiny hexagonal needles in the lepispheres formed. We have obtained similar morphologies in the lephispheric aggregates, although at higher temperature and basicity of the medium. The highly-symmetric hexagonal needle shape reflected CAN's hexagonal symmetry $(\mathrm{P} 63)^{40}$ and is an indication of high crystallinity. With reaction time, a small concentration of CAN is seen by XRD, although it is morphologically indistinguishable by SEM simply by grain size (Scherrer law, etc.).

Figure 8a-c show the main morphological features observed in the zeotypes synthesized from metakaolinite, typical cubic crystals of zeolite LTA (interpenetrationtwinning) and spheric aggregates of SOD. Figure 8d reveals solid spherical crystallites of SOD and residual metakaolinite. No needle-like crystals of SOD were observed.

\subsubsection{FT-IR analysis}

The FT-IR spectra of the starting materials and assynthesized products obtained after its hydrothermal treatment with alkaline solutions are shown in Figure 9. The characteristic vibrations bands of the starting materials disappeared with reaction time. In general, the characteristic bands of the starting materials shift of transmittance to lower wavenumbers indicates that there are more $\mathrm{Al}$ substitution in tetrahedral sites of the silica framework with $\mathrm{NaOH}$ acting as a structure modifier as reported in other studies ${ }^{41,42}$.

As shown in Figure 9a, the absorption bands of the synthesis products at low temperature show the asymmetric and symmetric vibration bands characteristic of a mixture of LTA zeolite, SOD, and CAN in the region 1200-400 $\mathrm{cm}^{-1}$. Barnes et al. ${ }^{4}$ summarized the reported assignments of

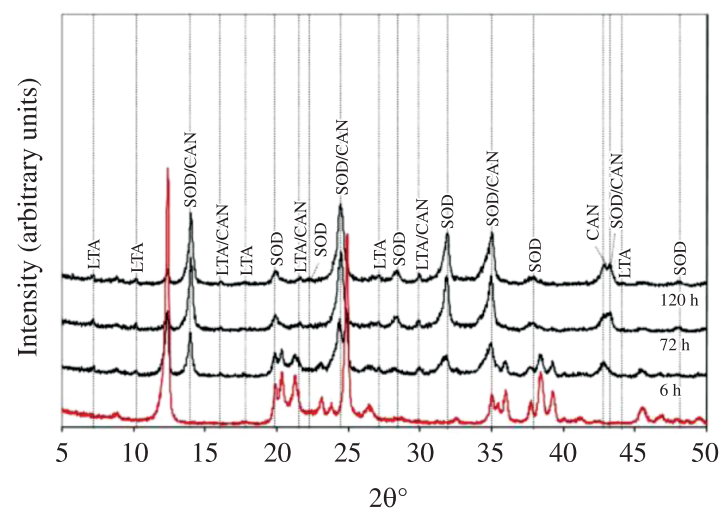

(a)

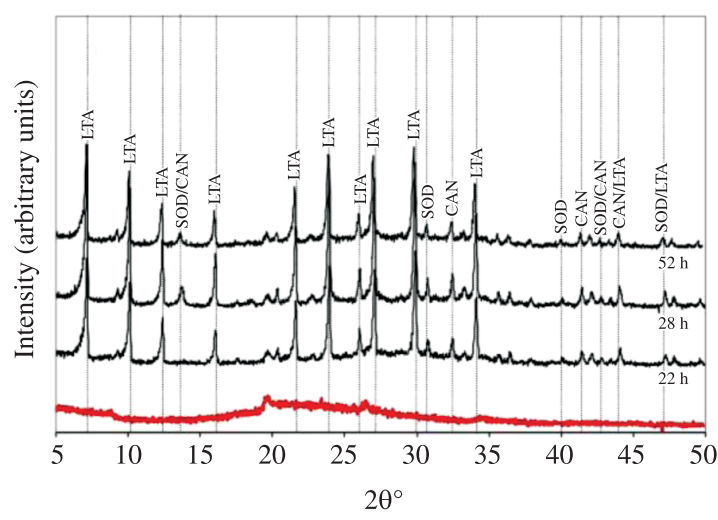

(b)

Figure 6. X-ray diffraction patterns of the as-synthesized zeotypes after reaction of the starting (a) kaolinite and (b) metakaolinite in 1.33 $\mathrm{M} \mathrm{NaOH}$ solutions at $100{ }^{\circ} \mathrm{C}$ for several times. 


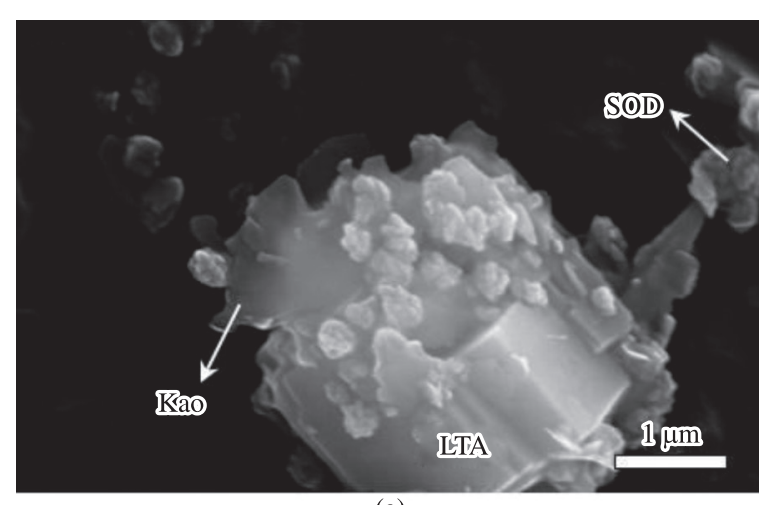

(a)

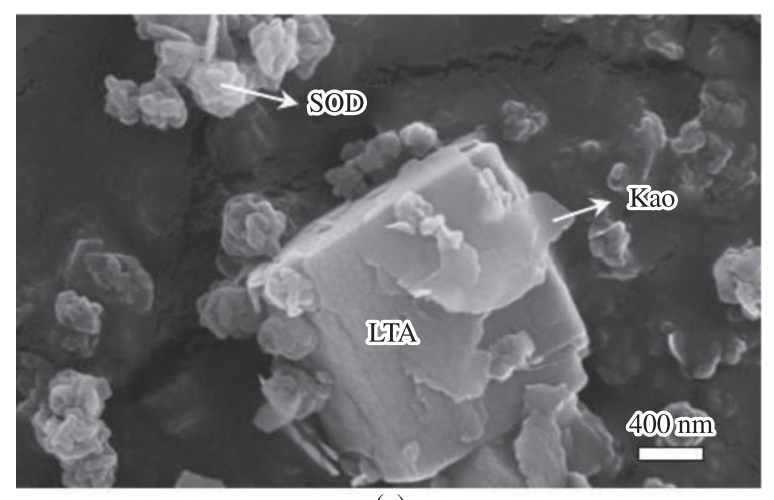

(c)

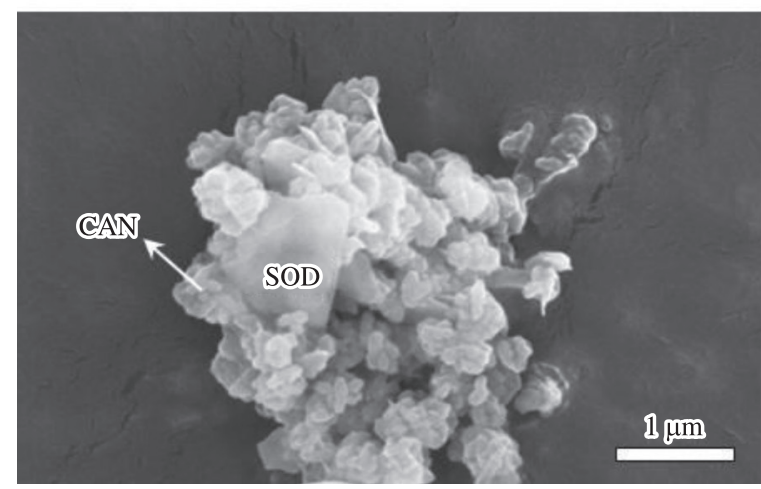

(e)

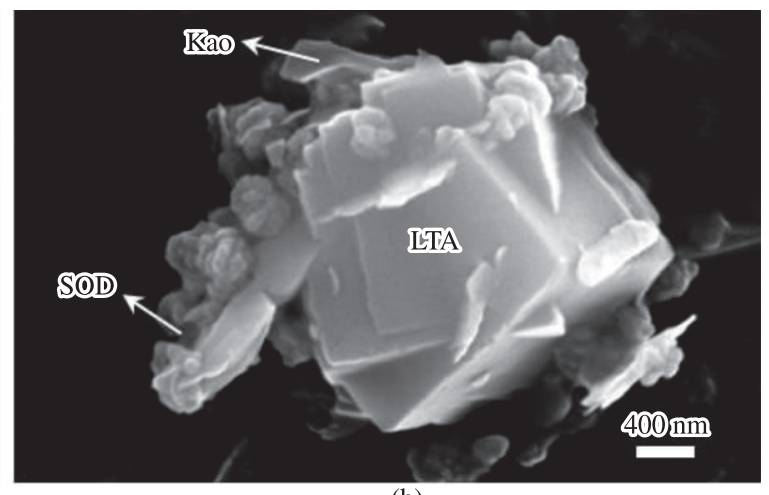

(b)

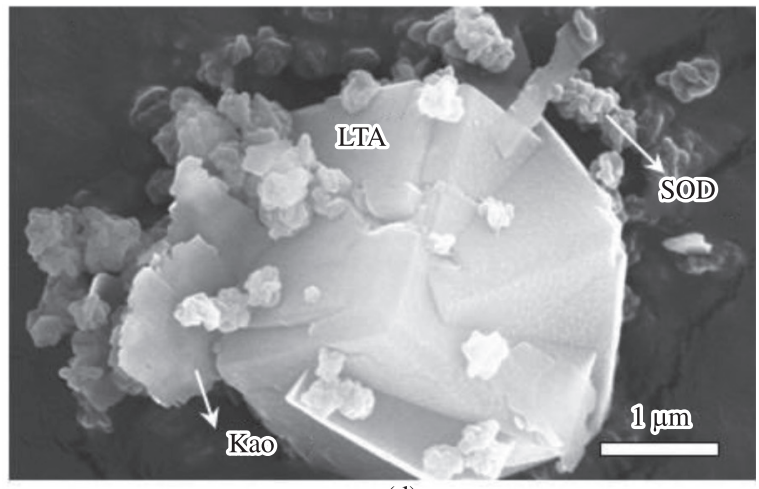

(d)

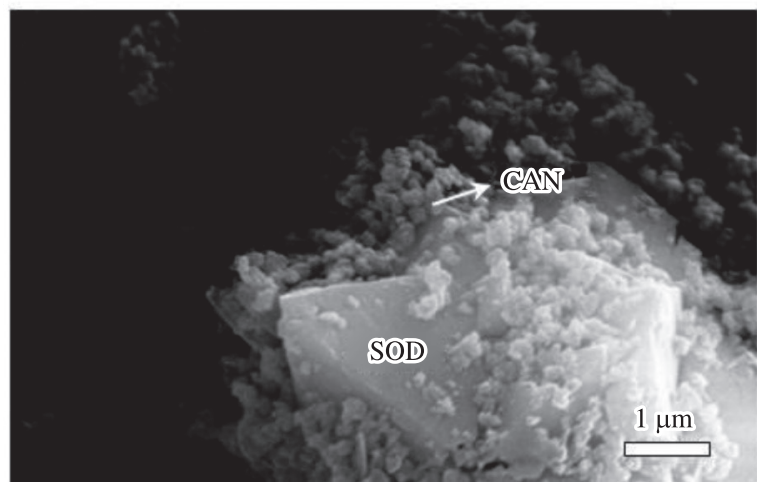

(f)

Figure 7. SEM images showing several synthesis products obtained by hydrothermal treatment of the starting kaolinite in (a)(b) $1.33 \mathrm{M}$ $\mathrm{NaOH}$ solutions, after 6 hours of reaction at $100{ }^{\circ} \mathrm{C}$, (c)(e) $1.33 \mathrm{M} \mathrm{NaOH}$ solutions, after 120 hours of reaction at $100{ }^{\circ} \mathrm{C}$, and (f) $3.99 \mathrm{M}$ $\mathrm{NaOH}$ solutions, after 120 hours of reaction at $100{ }^{\circ} \mathrm{C}$.

vibrations for SOD and CAN in this range. Coincident with the disappearance of kaolinite, characteristic zeolite bands appeared on the spectra, including the asymmetric Al-O stretch located in the region of $1250-950 \mathrm{~cm}^{-1}$, and their symmetric Al-O stretch located in the region of $770-660 \mathrm{~cm}^{-1}$. The region $1200-850 \mathrm{~cm}^{-1}$ shows a single vibration band centred at $960-965 \mathrm{~cm}^{-1}$, associated with the presence of CAN. The transmittance of the asymmetric stretch of the Si-O-Al in the SOD framework consists of a single band at $980 \mathrm{~cm}^{-1}$, which split into four bands at 1110 , 1050, 1020, and $960 \mathrm{~cm}^{-1}$ assigned to $\mathrm{CAN}^{4}$. However, this study reports only the bands at 975 and $960-965 \mathrm{~cm}^{-1}$, corresponding to SOD and CAN, respectively. The region
$850-750 \mathrm{~cm}^{-1}$ reveals a weak vibration band at $766-768 \mathrm{~cm}^{-1}$, characteristic of CAN. Several bands in the region 750$650 \mathrm{~cm}^{-1}$ indicate the presence of a mixture of SOD and $\mathrm{CAN}$ in the as-synthesized products. The bands in the region $650-500 \mathrm{~cm}^{-1}$ are related to the presence of the double rings (D4R and D6R) in the framework structures of the zeolitic materials ${ }^{9}$. The bands in the region $500-420 \mathrm{~cm}^{-1}$ are related to internal tetrahedron vibrations of $\mathrm{Si}-\mathrm{O}$ and $\mathrm{Al}-\mathrm{O}$ of the zeotypes. The region $800-400 \mathrm{~cm}^{-1}$ can be considered as the fingerprint region for zeolite LTA, SOD, and CAN as suggested in previous studies ${ }^{4,41}$. As shown in Figure 9b, The characteristic vibration bands of metakaolinite disappeared, accompanied by the appearance of new peaks that reveal 


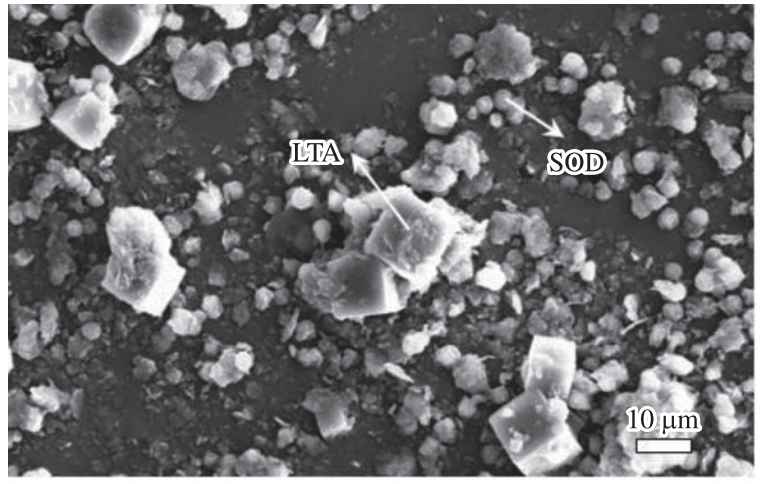

(a)

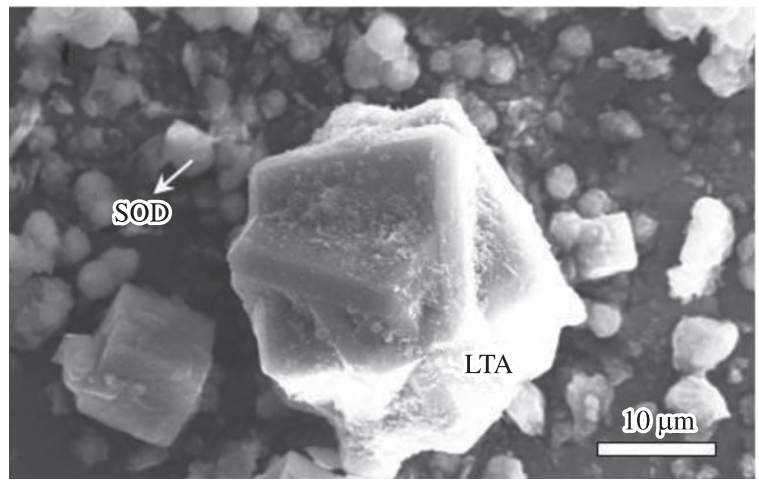

(c)

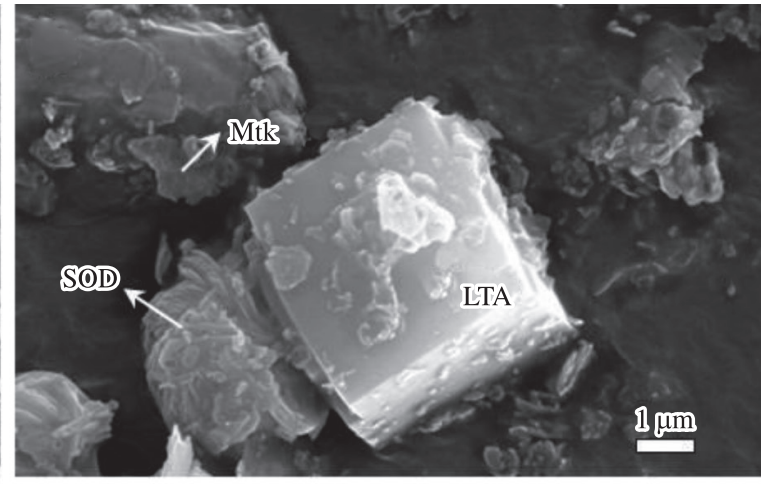

(b)

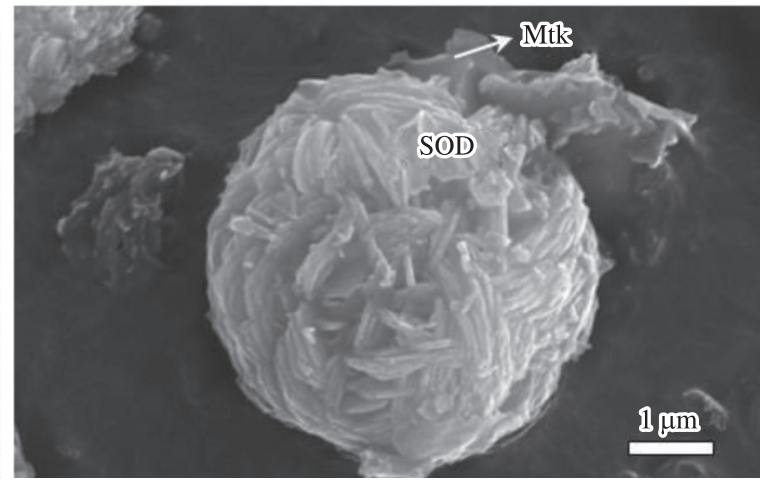

(d)

Figure 8. SEM images showing several synthesis products obtained by hydrothermal treatment of the starting metakaolinite in (a)(d) $1.33 \mathrm{M}$ $\mathrm{NaOH}$ solutions, after 52 hours of reaction at $100{ }^{\circ} \mathrm{C}$.

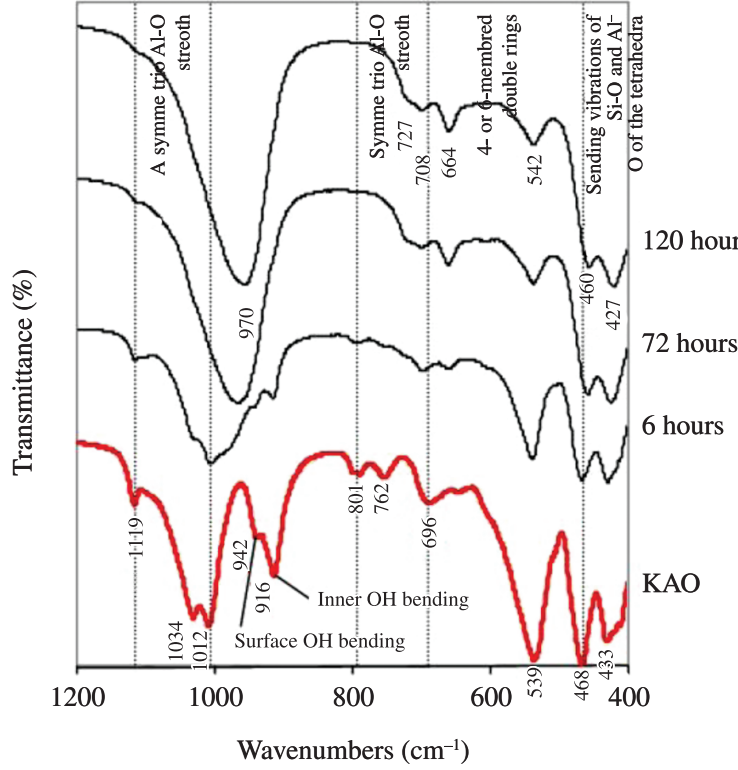

(a)

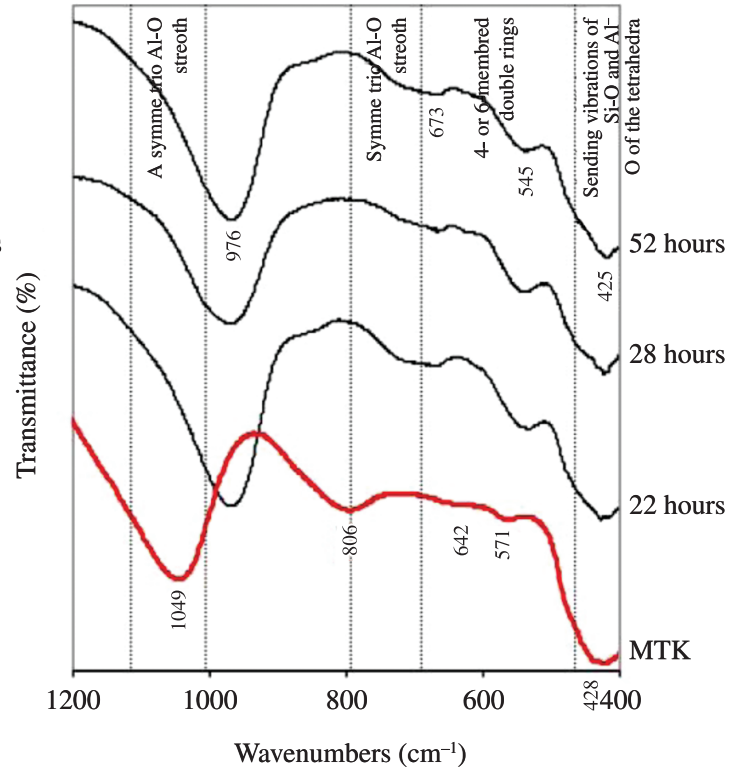

(b)

Figure 9. FTIR spectra of unreacted raw materials and the as-synthesized zeotypes obtained after hydrothermal transformation of (a) kaolinite and (b) metakaolinite in $1.33 \mathrm{M} \mathrm{NaOH}$ solutions at $100{ }^{\circ} \mathrm{C}$ after several reaction times. 
the occurrence of zeolite LTA. The band at $1047 \mathrm{~cm}^{-1}$ was shifted to lower frequency bands (at $973-980 \mathrm{~cm}^{-1}$ ); the band at $800 \mathrm{~cm}^{-1}$ disappeared in the zeolitic products; the low intensity bands at 635 and $565 \mathrm{~cm}^{-1}$ were shifted to higher (at 673-690 $\mathrm{cm}^{-1}$ ) and lower (at 530-538 $\mathrm{cm}^{-1}$ ) frequency bands, respectively. The band at $424 \mathrm{~cm}^{-1}$ was shifted to lower frequency bands (at $411-417 \mathrm{~cm}^{-1}$ ). The typical bands of zeolite LTA representing the asymmetric Al-O (973$\left.980 \mathrm{~cm}^{-1}\right)$ and symmetric Al-O $\left(673-690 \mathrm{~cm}^{-1}\right)$ stretches, double rings $\left(530-538 \mathrm{~cm}^{-1}\right)$ in the framework structures of the zeolitic materials were observed and they show a constant intensity. The FT-IR peak width is an indication of the level of the crystallinity of the synthesis products.

\subsection{4. ${ }^{29} \mathrm{Si}$ and ${ }^{27} \mathrm{Al}$ MAS-NMR}

Figure 10 shows the ${ }^{29} \mathrm{Si}$ and ${ }^{27} \mathrm{Al}$ MAS-NMR spectra of the starting kaolinite and representative as-synthesized zeotypes. The ${ }^{29} \mathrm{Si}$ MAS-NMR spectrum of the synthesis products show three resonances at $-83.6,-86.3$ and -91.2 ppm. The chemical shifts at -83.6 and -86.3 ppm can be attributed to $\mathrm{Q}^{4}(4 \mathrm{Al})$ environments in SOD and $\mathrm{CAN}^{43}$. The presence of the two $\mathrm{Si}$ sites indicates imperfect $\mathrm{Al} /$ $\mathrm{Si}$ ordering in tetrahedral sites. CAN was reported to have a chemical shift of $-87.3 \mathrm{ppm}^{4}$. Therefore, in this study the signal at $-86.3 \mathrm{ppm}$ can be presumably attributed to CAN. In some studies, ${ }^{29} \mathrm{Si}$ MAS-NMR has been used to differentiate between SOD and $\mathrm{CAN}^{44,45}$. However, according to Barnes et al. ${ }^{4}$, no difference in chemical shift between these zeotypes can be recognized in terms of ${ }^{29} \mathrm{Si}$ MAS-NMR. The -91.2 ppm chemical shift can be assigned to the presence of residual kaolinite. The ${ }^{27} \mathrm{Al}$ MAS-NMR spectrum of the synthesis products shows a single resonance at $59.5 \mathrm{ppm}$, which can be assigned to tetrahedral $\mathrm{Al}$ in the framework of the zeotypes, but with some octahedral $\mathrm{Al}$ corresponding to the presence of residual kaolinite. The reaction of the kaolinite with $\mathrm{NaOH}$ as mineralizer resulted in a shift of $\mathrm{Al}$ from octahedral to tetrahedral coordination, which is likely due to the dissolution of this clay mineral and the subsequent precipitation of the zeotypes. The amount of $\mathrm{Al}(6)$ is greatest in kaolinite (Figure 10a) where the initial Al concentration was larger compared with that in the synthesis products (Figure 10b). The decrease in the $\mathrm{Al}(6) / \mathrm{Al}(4)$ ratio can be explained by the dissolution of kaolinite, with $\mathrm{Al}$ coordination changing from octahedral to tetrahedral, which is consistent with the formation of zeolite-type materials.

Figure 11 shows the ${ }^{29} \mathrm{Si}$ and ${ }^{27} \mathrm{Al}$ MAS-NMR spectra of the starting metakaolinite and representative as-synthesized zeotypes. The ${ }^{29} \mathrm{Si}$ MAS-NMR spectrum of the synthesis products shows a sharp signal at $-89.5 \mathrm{ppm}$, which is characteristic of $\mathrm{Q}^{4}(4 \mathrm{Al})$ sites in zeolite LTA, similar to that observed by Akolekar et al. ${ }^{20}$. A weak signal at $-85.9 \mathrm{ppm}$ can be attributed to the contribution of $\mathrm{Q}^{4}(4 \mathrm{Al})$ sites of SOD and CAN. ${ }^{29} \mathrm{Si}$ MAS-NMR results point out the change of the silica morphology from amorphous $\mathrm{SiO}_{2}$ in the metakaolinite to crystalline $\mathrm{SiO}_{2}$ in the zeotypes, with the total dissolution of the starting metakaolinite to form zeolite-type structures and the incorporation of aluminium. The ${ }^{27} \mathrm{Al} \mathrm{MAS-NMR}$ spectrum of the synthesis products shows a single resonance at $58.2 \mathrm{ppm}$, which can be assigned to tetrahedral $\mathrm{Al}$ in the zeotypes.
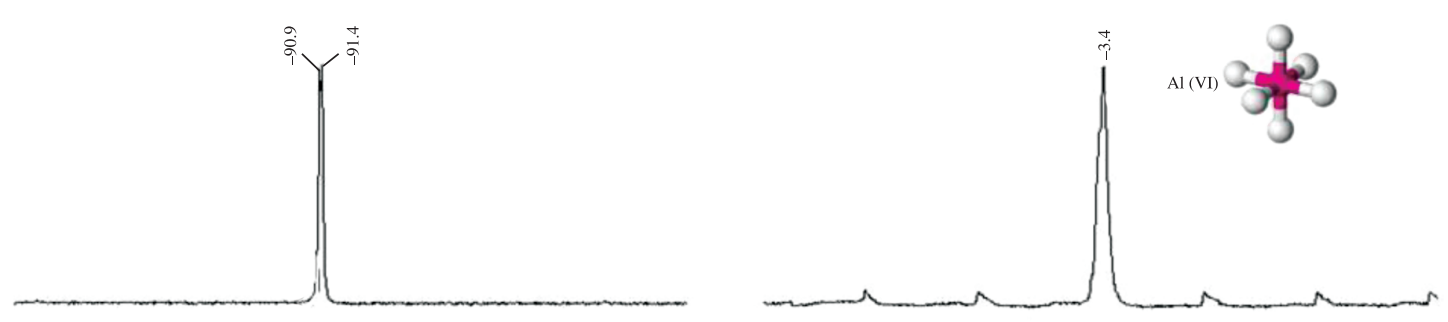

(a)
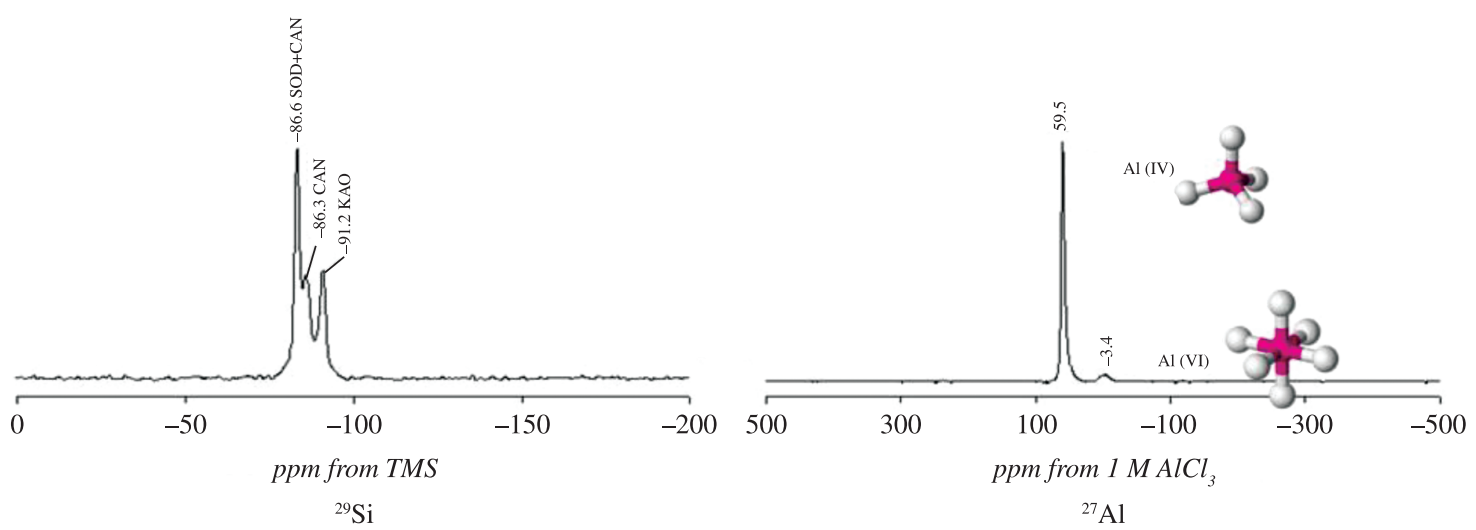

(b)

Figure 10. ${ }^{29} \mathrm{Si}$ and ${ }^{27} \mathrm{Al}$ MAS-NMR spectra of the (a) starting kaolinite and (b) representative as-synthesized zeotypes obtained after hydrothermal transformation of kaolinite in $1.33 \mathrm{M} \mathrm{NaOH}$ solutions at $100{ }^{\circ} \mathrm{C}$ after 120 hours of reaction. 

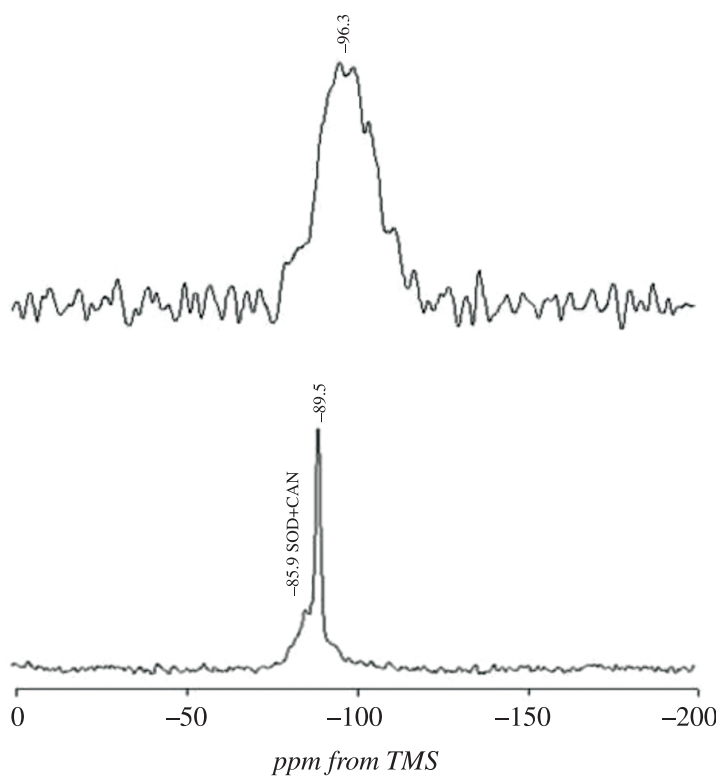

${ }^{29} \mathrm{Si}$ (a)
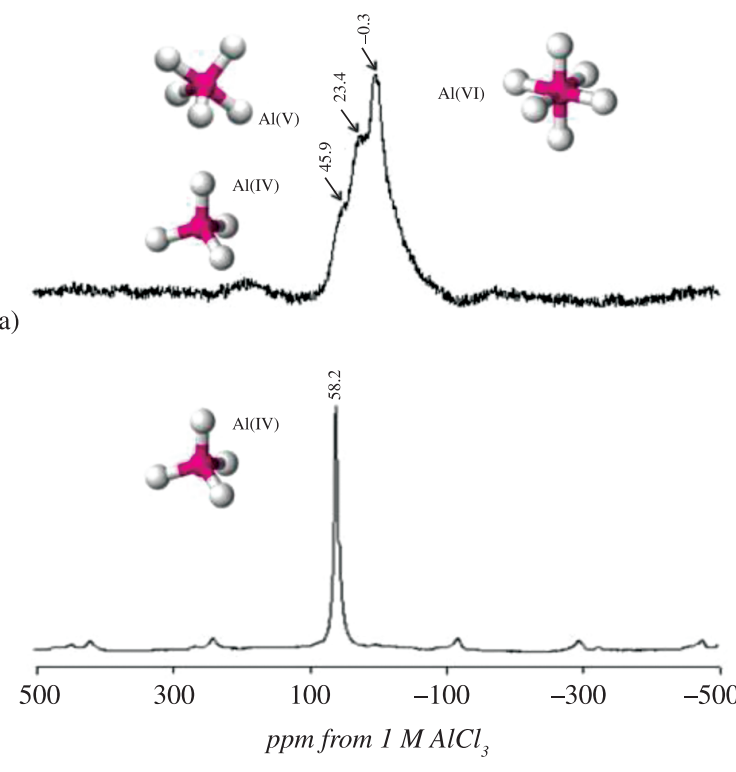

${ }^{27} \mathrm{Al}$

(b)

Figure 11. ${ }^{29} \mathrm{Si}$ and ${ }^{27} \mathrm{Al}$ MAS-NMR spectra of the (a) starting metakaolinite and (b) representative as-synthesized zeotypes obtained after hydrothermal transformation of metakaolinite in $1.33 \mathrm{M} \mathrm{NaOH}$ solutions at $100{ }^{\circ} \mathrm{C}$ after 52 hours of reaction.

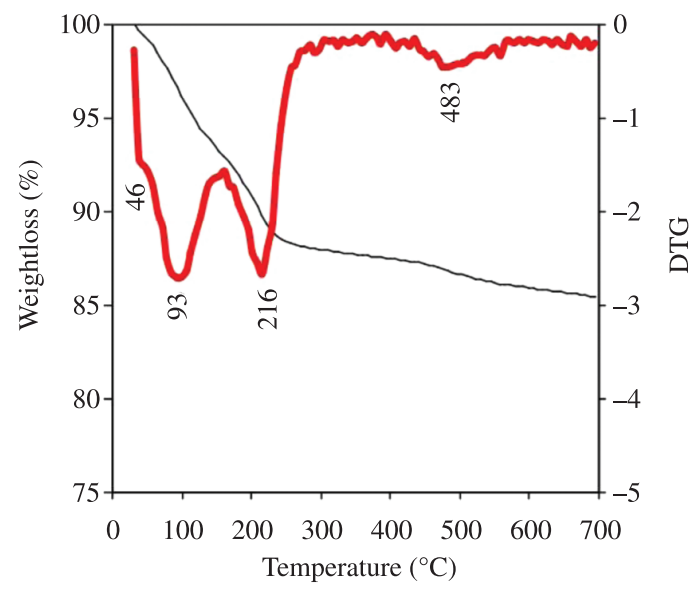

(a)

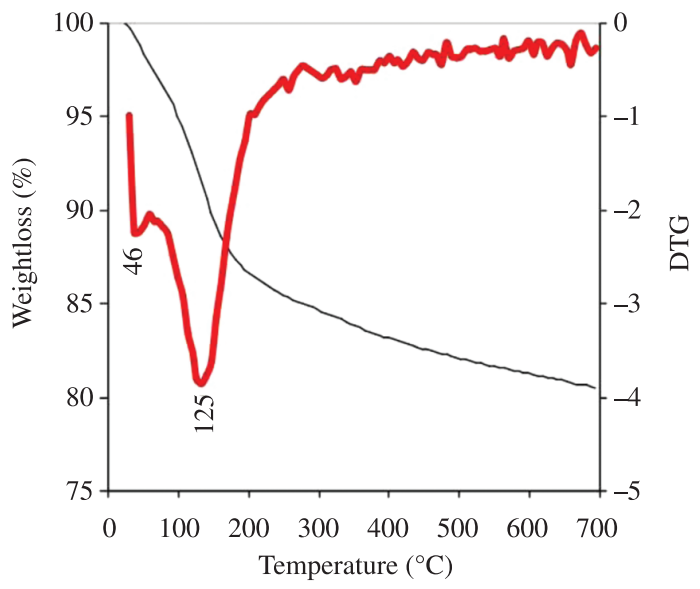

(b)

Figure 12. TG/DTG curves from 25 to $700{ }^{\circ} \mathrm{C}$ of the representative as-synthesized zeotypes obtained after hydrothermal transformation of (a) kaolinite and (b) metakaolinite in $1.33 \mathrm{M} \mathrm{NaOH}$ solutions at $100{ }^{\circ} \mathrm{C}$ after 120 hours and 52 hours of reaction, respectively.

\subsubsection{TG analysis}

DTG curves of the representative as-synthesized zeotypes are shown in Figure 12. The synthesis products show up to four dehydration steps. The position of these DTG peaks and the number of dehydration steps can be attributed to the different compensating cation-water binding energies as well as to the different energy associated with the diffusion of the desorbed water through the porous structure of the as-synthesized products; their weight loss percentages reflects the water loss from the zeolite structure, and the amount of desorbed water is related with the number of compensation cations in the framework of the zeolite ${ }^{46}$. The peaks observed between $39-52^{\circ} \mathrm{C}$ correspond to surface water in zeolitic materials; the peaks observed between $100-162{ }^{\circ} \mathrm{C}$ indicate zeolitic water, although in some cases in this temperature range up to two peaks occur, which can be explained by the heterogeneous nature of the assynthesized products.

\subsection{Phase transformation from SOD to CAN}

The $\mathrm{SOD}$ and $\mathrm{CAN}$ zeotypes present a ratio of $\mathrm{Si} / \mathrm{Al}=1$, being one of the few structures that have compensation 
anions ${ }^{47}$. Therefore, it is not surprising that they can be synthesized under similar conditions. The formation of a specific structure (SOD-type or CAN-type), depends on, among other factors, the symmetry, the charge of the anion and the basicity of the medium ${ }^{47}$. Walton et al. ${ }^{48}$ studied on the influence of the reaction condition of the hydrothermal crystallization and the transformation of zeolite LTA into SOD by time resolved in situ energy dispersive $\mathrm{X}$ ray diffraction.

According to Barnes et al. ${ }^{2}$, the phase transformation from SOD to CAN was a solution-mediated process, which involved a four-stage mechanism: (1) dissolution of $\mathrm{SOD},(2)$ relative CAN supersaturation as a result of SOD dissolution, (3) nucleation of CAN, and (4) simultaneous growth of CAN nuclei and dissolution of SOD.

Results from this study are in agreement with regard to SOD forms first and then transforms slowly to CAN at a rate that increases with increasing temperature ${ }^{4,17}$. Consequently, the formation of these aluminosilicate phases may be considered as being dominated by kinetics rather than thermodynamics ${ }^{2}$.

A mixture of LTA zeolite, SOD, and CAN was obtained at $100{ }^{\circ} \mathrm{C}$, as demonstrated by XRD patterns shown in Figure 2. The formation of these zeolitic materials is in agreement with the previous study by Ríos et al. ${ }^{14}$, which suggest that zeolite LTA is the main zeolitic phase at shorter reaction times, whereas SOD- and CAN-type structures were formed from hydrogels at longer reaction times.

\subsection{Nucleation and growth process of SOD and $C A N$}

During recent years, several research groups have made great efforts to successfully bridge the gap between the general formation mechanisms of crystalline phases and the crystallization of complex structures, such as those of zeolites $^{49}$. However, specific information concerned with crystallization mechanism and kinetics is limited ${ }^{9}$. The chemistry of evolution of relatively simple zeolite systems, can be affected by several factors, such as the formation of intermediate metastable phases (e.g. zeolite LTA), the occurrence of simultaneous reactions such as precipitation and dissolution of a gel phase, nucleation and growth of zeotypes, dissolution of the early metastable phases, nucleation and growth of more stable phases such as SOD and CAN, with a dissolution of the initial crystals, and nucleation and growth of the crystalline phases that reached chemical equilibrium. However, the reaction history of the zeolite synthesis developed in this study can be summarized as follows.

The process of synthesis can be described by two main stages: (1) the dissolution of aluminosilicate compounds releasing $\mathrm{Si}$ and $\mathrm{Al}$ and (2) the zeolite crystallization. Zeolites are typically crystallized from amorphous aluminosilicate precursors in aqueous in the presence of alkali metals. A simple scheme of the crystallization of an amorphous aluminosilicate hydrogel to SOD and CAN is given in Figure 13.

At the beginning of the synthesis process, a dissolution of the starting materials occurred, with the production of an amorphous gel characterized by the presence of small olygomers (Figure 13a). A dissolution process promotes the formation of the nutrients (ionic species) which then are transported to the nucleation sites, indicating that the ionic species are not static, because they necessarily need to move (transportation) to the nucleation sites. A nucleation process (Figure 13b) produced an equilibrated gel. During nucleation, hydrogel composition and structure are significantly affected by thermodynamic and kinetic parameters. A polymerization of $\mathrm{SiO}_{4}$ tetrahedra proceed (Figure 13c), which is represented by $\mathrm{TO}_{4}$ primary tetrahedral building units have been joined, revealing how they link together to form larger structures. A polymerization is the process that forms the zeolite precursors, which contains tetrahedral of $\mathrm{Si}$ and $\mathrm{Al}$ randomly distributed along the polymeric chains that are cross-linked so as to provide cavities large enough to accommodate the charge balancing alkali ions. During crystal growth (Figure 13d) the $\mathrm{TO}_{4}$ units were linked, with the formation of 4-ring and 6-ring, composed by 4 and 6 tetrahedral atoms, respectively, to create a large structure (secondary building unit) like the SOD $\beta$-cage. The crystallization of zeolite LTA occurred by linking the same secondary building units together (Figure 13e). A phase transformation occurred as represented by the sequence of reaction: zeolite LTA $\rightarrow$ $\mathrm{SOD} \rightarrow \mathrm{CAN}$ (Figure 13f).

According to Breck ${ }^{9}$, the hydrogel composition and structure is controlled by the size and structure of the polymerization species and gelation controls the nucleation of the zeolite crystallites, which is supported by the crystal size and morphology of zeolites grown from hydrogels. It is clear from data reported by Barnes et al. ${ }^{2}$ that at lower temperature and $\mathrm{NaOH}$ concentration than those used in this study zeolite LTA transforms to zeolite P. We consider that SOD should appear after zeolite LTA without the formation of zeolite P. However, Ríos ${ }^{15}$ reported the co-crystallization of SOD + CAN, which was followed by the crystallization of the JBW-type structure at higher temperature and $\mathrm{NaOH}$ concentration. Ogura et al. ${ }^{50}$ reported that cyclic tetramer and hexamer species could be found in the liquid phase to generate SOD cages. SOD nucleated homogeneously in the liquid phase and grown without intervention of hydroge ${ }^{51}$. On the other hand, results reported by Lee et al. ${ }^{51}$ clearly explain that SOD crystallization takes place by the solidsolid transformation without involving any solution or amorphous-mediated process. However, the transformation of SOD to CAN involves a solution-mediated mechanism with SOD dissolution and subsequent CAN precipitation as suggested by Barnes et al. ${ }^{2}$. They also demonstrated that CAN is formed at expense of two dimorphs of cubic SOD, which show a notable change in unit cell size as reported by Zheng et al. ${ }^{17}$.

The mineral transformations and the stability of the end products were controlled by experimental parameters like $\mathrm{NaOH}$ concentration, temperature and $\mathrm{Si} / \mathrm{Al}$ ratio. However, they were likely affected by several factors, such as the formation of intermediate metastable phases and the occurrence of different chemical processes, including precipitation and dissolution of a gel phase, nucleation and growth of zeotypes, dissolution of the early metastable phases, nucleation and growth of more stable phases (SOD 


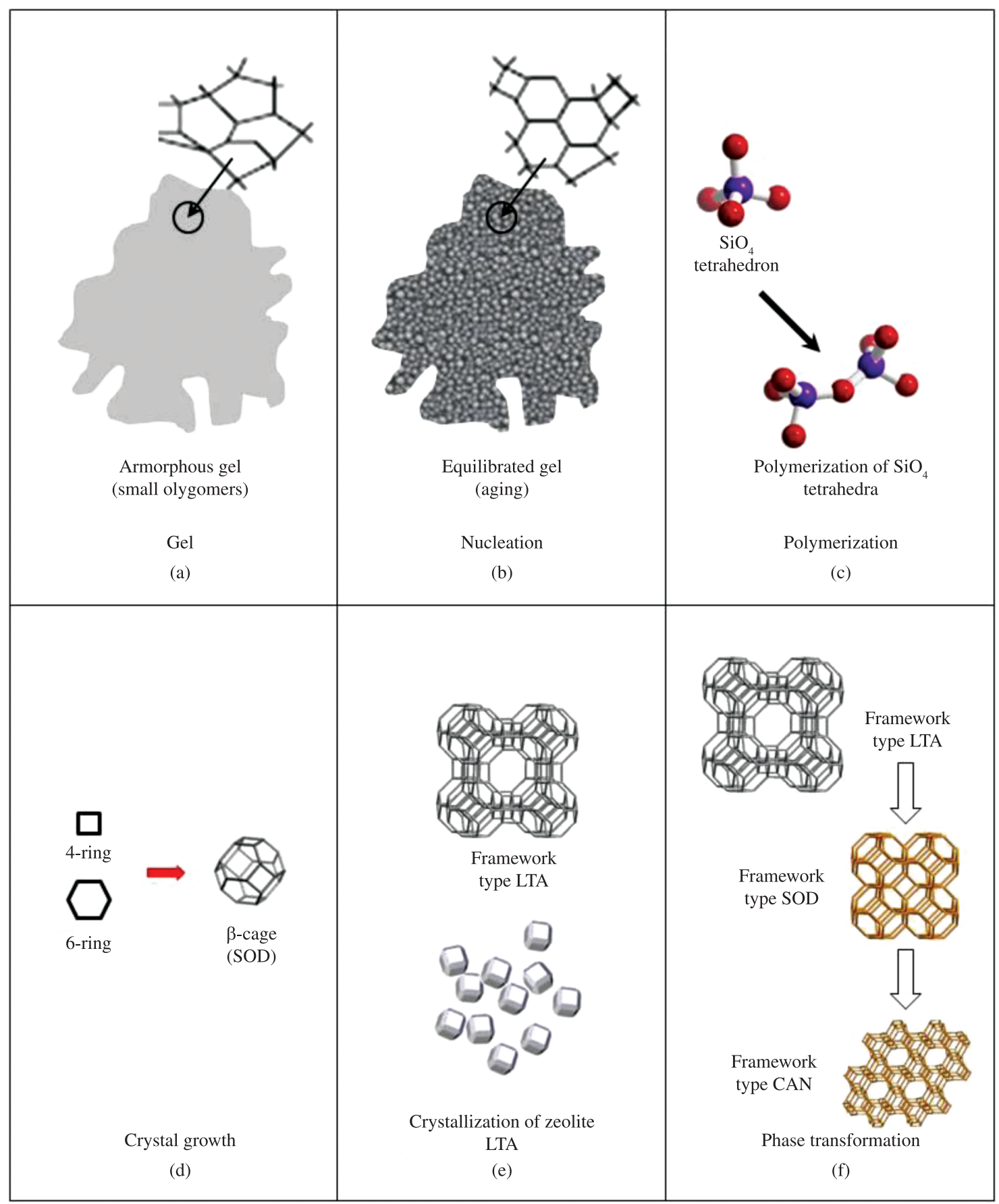

Figure 13. Illustration of the proposed sequence for the formation of zeotypes.

and CAN), with a dissolution of the initial crystals and nucleation and growth of the crystalline phases that reached chemical equilibrium.

Ríos et al. ${ }^{6,14,15}$ have demonstrated that the occurrence of a sequence of chemical reactions from amorphous aluminosilicate gel to crystalline zeotypes, which can be summarized as follows:

Poorly crystalline aluminosilicate $\rightarrow$ zeolite LTA $\rightarrow$ $\mathrm{SOD} \rightarrow \mathrm{SOD}+\mathrm{CAN} \rightarrow \mathrm{CAN}$.
The hydrothermal transformation of the starting kaolinite and metakaolinite at low temperature presumably reveals a similar sequence of reactions, starting with an amorphous material after dissolution of the aluminosilicate phases, followed by zeolite LTA as the first and metastable phase formed, SOD-type structure, a mixture of SOD-type and CAN-type structures and finally CAN (apparently more stable than SOD) as the stable and final synthesis product. However, according to Barnes et al. ${ }^{2}$, CAN appeared more 
stable than SOD, concluding that CAN would be the final product, whereas amorphous material, zeolite LTA and SOD would be transition phases. Fechtelkord et al. ${ }^{52}$ argued that SOD is the thermodynamically more stable phase and CAN formation is kinetically favored at lower $\mathrm{NaOH}$ concentrations. Similar results can be assumed in this study. We are in agreement with the fact that these phase transformations did not occur in the solid state and, therefore, represent a solution-mediated mechanism as suggested by previous studies ${ }^{2,39}$. According to XRD data a co-crystallization of zeolite LTA, SOD and CAN occurs, being very difficult to evaluate phase transformations due to the very constant behaviour of the XRD peaks of these zeotypes and to the overlapping of peaks of SOD-type and CAN-type structures, which makes difficult to quantifying SOD and CAN mixtures. However, SEM data reveal phase relationships in which (1) lepispheric aggregates of SOD and CAN grow onto the surface of cubic crystals of zeolite LTA or (2) CAN grows at the expense of SOD. Under the experimental conditions considered by Deng et al. ${ }^{39}$ there is enough evidence about phase transformations that occur in this chemical system. However, in this study a slight higher temperature $\left(100{ }^{\circ} \mathrm{C}\right)$ was used, which can explain why zeolite LTA (a metastable phase) occurs as a minor phase, compared with the presence of SOD and CAN.

\section{Conclusions}

Zeotypes such a s SOD and CAN were successfully synthesized via hydrothermal treatment using kaolinite and metakaolinite as starting materials and $\mathrm{NaOH}$ as activating agent. However, zeotype formation was assessed to be fairly

\section{References}

1. Barnes MC, Addai-Mensah J and Gerson AR. The solubility of sodalite and cancrinite in synthetic spent Bayer liquor. Colloids and Surfaces A: Physicochemical and Engineering Aspects. 1999; 157:106-116. http://dx.doi.org/10.1016/S09277757(99)00058-8

2. Barnes MC, Addai-Mensah $\mathrm{J}$ and Gerson AR. The mechanism of the sodalite-to-cancrinite phase transformation in synthetic spent Bayer liquor. Microporous and Mesoporous Materials. 1999; 31:287-302. http://dx.doi.org/10.1016/S13871811(99)00079-7

3. Xu B, Smith P, Wingate C and De Silva L. The effect of calcium and temperature on the transformation of sodalite to cancrinite in Bayer digestion. Hydrometallurgy. 2010; 105:75-81. http:// dx.doi.org/10.1016/j.hydromet.2010.07.010

4. Barnes MC, Addai-Mensah J and Gerson AR. A methodology for quantifying sodalite and cancrinite phase mixtures and the kinetics of the sodalite to cancrinite phase transformation. Microporous and Mesoporous Materials. 1999; 31:303-319. http://dx.doi.org/10.1016/S1387-1811(99)00080-3

5. Barrer RM. Zeolites and Clay Minerals as Sorbents and Molecular Sieves. London: Academic Press; 1978.

6. Ríos CA, Williams C and Fullen MA. Nucleation and growth history of zeolite LTA synthesized from kaolinite by two different methods. Applied Clay Science. 2009; 42:446-454. http://dx.doi.org/10.1016/j.clay.2008.05.006 unsuccessful via zeolite LTA, taking into account that the synthesis products area characterized by the occurrence of SOD and CAN as metastable phases. The structural similarity between zeolites and feldspathoids explain why they can coexist in the as-synthesized products and the dominant crystalline phase depends on formation conditions. The main crystalline phases obtained after synthesis process were zeolite LTA, SOD and CAN. The synthesis products are strongly controlled by the starting material, taking into account that metakaolinite is a more reactive phase than kaolinite. There were two major chemical processes involved in the reaction between the starting kaolinite and metakaolinite and alkaline solutions: dissolution of the starting materials followed by the formation of zeolitic materials. Future research, should consider to develop further experiments under well-optimized conditions for obtaining individual phases instead of mixtures, and evidently in order to clarify the sequence of phase crystallization.

\section{Acknowledgements}

We thank the Programme Alban, the European Union Programme of High Level Scholarships for Latin America, scholarship No. E05D060429CO, and the Universidad Industrial de Santander for funding C.A. Ríos. Special thanks to School of Applied Sciences at University of Wolverhampton for allowing us the use of the research facilities. We thank Dr Townrow and Mrs Hodson for assistance in collecting XRD and SEM data, respectively, and Dr Apperley at the University of Durham for MASNMR spectra.
7. Zeolite Structures. Database. Available from: <http://www. iza-structure.org/databases/>.

8. Heller-Kallai L and Lapides I. Reactions of kaolinites and metakaolinites with $\mathrm{NaOH}$ - Comparison of different samples (Part 1). Applied Clay Science. 2007; 35:99-107. http://dx.doi. org/10.1016/j.clay.2006.06.006

9. Breck DW. Zeolite Molecular Sieves: Structure, Chemistry and Use. New York: John Wiley; 1974.

10. Chandrasekhar S and Pramada PN. Investigation on the synthesis of zeolite NaX from Kerala kaolin. Journal of Porous Materials. 1999; 6:283-297. http://dx.doi. org/10.1023/A:1009632606671

11. Mackenzie RC. Differential Thermal Analysis 1. London: Academic Press; 1970.

12. Rocha J, Klinowski J and Adams JM. Synthesis of zeolite Na-A from metakaolinite revisited. Journal of the Chemical Society, Faraday Transactions. 1991; 87:3091-3097. http:// dx.doi.org/10.1039/ft9918703091

13. Lapides I and Heller-Kallai L. Reactions of metakaolinite with $\mathrm{NaOH}$ and colloidal silica - Comparison of different samples (Part 2). Applied Clay Science. 2007; 35:94-98. http://dx.doi. org/10.1016/j.clay.2006.06.007

14. Ríos CA, Williams CD and Maple MJ. Synthesis of zeolites and zeotypes by hydrothermal transformation of kaolinite and metakaolinite. Bistua. 2007; 5:15-26. 
15. Ríos CA. Synthesis of zeolites from geological materials and industrial wastes for potential application in environmental problems. [Thesis]. Wolverhampton: University of Wolverhampton; 2008.

16. Zheng K, Smart RSC, Addai-Mensah J and Gerson AR. The solubility of sodium aluminosilicates in synthetic Spent Bayer liquor. Journal of Chemical \& Engineering Data. 1998; 43:312-317. http://dx.doi.org/10.1021/je970187i

17. Zheng K, Gerson AR, Addai-Mensah J and Smart RSC. The influence of sodium carbonate on aluminosilicate crystallization and solubility in sodium aluminate solutions. Journal of Crystal Growth. 1997; 171:197-208. http://dx.doi. org/10.1016/S0022-0248(96)00480-0

18. Breuer RG and Barsotti LR. Kelly AC. Extractive Metallurgy of Aluminium. Interscience. 1963; 7:133-157.

19. Zhao H, Deng Y, Harsh JB, Flury M and Boyle JS. Alteration of Kaolinite to Cancrinite and Sodalite by Simulated Hanford Tank Waste and its impact on Cesium retention. Clays and Clay Minerals. 2004; 52:1-13. http://dx.doi.org/10.1346/ CCMN.2004.0520101

20. Akolekar D, Chaffee A and Howe RF. The transformation of kaolin to low-silica X zeolite. Zeolites. 1997; 19:359-365. http://dx.doi.org/10.1016/S0144-2449(97)00132-2

21. Murat M, Amokrane A, Bastide JP and Montanaro L. Synthesis of zeolites from thermally activated kaolinite. Some observations on nucleation and growth. Clay Minerals. 1992; 27:119-130. http://dx.doi.org/10.1180/claymin.1992.027.1.12

22. Van der Marel HW and Beutelspacher H. Atlas of Infrared Spectroscopy of Clay Minerals and Their Admixtures. Amsterdam: Elsevier; 1976.

23. Frost RL, Mako E, Krsitof J and Kloprogge JT. Modification of kaolinite surfaces through mechanochemical treatment - a midIR and near-IR spectroscopic study. Spectrochimica Acta Part A: Molecular and Biomolecular Spectroscopy. 2002; 58:28492859. http://dx.doi.org/10.1016/S1386-1425(02)00033-1

24. Hoch M and Bandara A. Determination of the adsorption process of tributyltin (TBT) and monobutyltin (MBT) onto kaolinite surface using Fourier transform infrared (FT-IR) spectroscopy. Colloids and Surfaces A: Physicochemical and Engineering Aspects. 2005; 253:117-124. http://dx.doi. org/10.1016/j.colsurfa.2004.10.118

25. Qiu G, Jiang T, Li G, Fan X and Huang Z. Activation and removal of silicon in kaolinite by thermochemical process. Scandinavian Journal of Metallurgy. 2004; 33:121-128. http:// dx.doi.org/10.1111/j.1600-0692.2004.00677.x

26. Lambert JF, Minman WS and Fripiat JJ. Revisiting kaolinite dehydroxylation: A silicon-29 and aluminum-27 MAS NMR study. Journal of the American Chemical Society. 1989; 111:3517-3522. http://dx.doi.org/10.1021/ ja00192a005

27. Thompson JG and Barron PF. Further consideration of the ${ }^{29} \mathrm{Si}$ nuclear magnetic resonance spectrum of kaolinite. Clays and Clay Minerals. 1987; 35:38-42. http://dx.doi.org/10.1346/ CCMN.1987.0350105

28. Letaief S, Elbokl TA and Detellier C. Reactivity of ionic liquids with kaolinite: Melt intersalation of ethyl pyridinium chloride in an urea-kaolinite pre-intercalate. Journal of Colloid and Interface Science. 2006; 302:254-258. http://dx.doi. org/10.1016/j.jcis.2006.06.008

29. Smith JV and Blackwell CS. Nuclear magnetic resonance of silica polymorphs. Nature. 1983; 303:223-225. http://dx.doi. org/10.1038/303223a0
30. Rocha $\mathrm{J}$ and Klinowski $\mathrm{J} .{ }^{29} \mathrm{Si}$ and ${ }^{27} \mathrm{Al}$ magic-angle-spinning NMR studies of the thermal transformation of kaolinite. Physics and Chemistry of Minerals. 1990; 17:179-186.

31. Mackenzie KJD, Brown IWM, Meinhold RH and Bowden ME. Outstanding problems in the kaolinite-mullite reaction sequence investigated by ${ }^{29} \mathrm{Si}$ and ${ }^{27} \mathrm{Al}$ Solid-State Nuclear Magnetic Resonance: I. Metakaolinite. Journal of the American Ceramic Society. 1985; 68:293-297. http://dx.doi. org/10.1111/j.1151-2916.1985.tb15228.x

32. Rocha R. Single- and triple-quantum ${ }^{27}$ Al MAS NMR study of the thermal transformation of kaolinite. Journal of Physical Chemistry B. 1999; 103:9801-9804. http://dx.doi.org/10.1021/ jp991516b

33. Liu Q, Spears DA and Liu Q. MAS NMR study of surfacemodified calcined kaolin. Applied Clay Science. 2001; 19:8994. http://dx.doi.org/10.1016/S0169-1317(01)00057-6

34. Balek V and Murat M. The emanation thermal analysis of kaolinite clay minerals. Thermochimica Acta. 1996; 282283:385-397. http://dx.doi.org/10.1016/0040-6031(96)02886-9

35. Frost RL, Horváth E, Makóc E, Kristóf J and Rédey A. Slow transformation of mechanically dehydroxylated kaolinite to kaolinite - an aged mechanochemically activated formamide - intercalated kaolinite study. Thermochimica Acta. 2003; 408:103-113. http://dx.doi.org/10.1016/S00406031(03)00316-2

36. Varga G. The structure of kaolinite and metakaolinite. Építoanyag. 2007; 59:4-8.

37. Chakravorty AK and Ghosh DK. Kaolinite-mullite reaction series: The development and significance of a binary aluminosilicate phase. Journal of the American Ceramic Society. 1991; 74:1401-1406. http://dx.doi. org/10.1111/j.1151-2916.1991.tb04119.x

38. Subotic B, Masic N and Smit I. Analysis of Particulate Processes During the Transformation of Zeolite A into Hydroxysodalite. In: Drzaj B, Hocevar S and Pejovnik S, editors. Zeolites - Synthesis, Structure, Technology and Application Studies in Surface Science and Catalysis. Amsterdam: Elsevier; 1985. vol. 24.

39. Deng Y, Flury M, Harsh JB, Felmy AR and Qafoku O. Cancrinite and sodalite formation in the presence of cesium, potassium, magnesium, calcium and strontium in Hanford tank waste stimulants. Applied Geochemistry. 2006; 21:2049-2063. http://dx.doi.org/10.1016/j.apgeochem.2006.06.019

40. Buhl JC, Stief F, Fechtelkord M, Gesing TM, Taphorn U and Taake C. Synthesis, X-ray diffraction and MAS NMR characteristics of nitrate cancrinite $\mathrm{Na}_{7} \cdot 6\left[\mathrm{AlSiO}_{4}\right]_{6}\left(\mathrm{NO}_{3}\right) 1.6\left(\mathrm{H}_{2} \mathrm{O}\right)_{2}$. Journal of Alloys and Compounds. 2000; 305:93-102. http://dx.doi. org/10.1016/S0925-8388(00)00724-6

41. Aronne A, Esposito S and Pernice P. FT-IR and DTA study of lanthanum aluminosilicates glasses. Materials Chemistry and Physics. 1997; 51:163-168. http://dx.doi.org/10.1016/ S0254-0584(97)80287-8

42. Aronne A, Esposito S, Ferone C, Pansini M and Pernice P. FT-IR study of the thermal transformation of bariumexchanged zeolite A to celsian. Journal of Materials Chemistry. 2002; 12:3039-3045. http://dx.doi.org/10.1039/ b203859e

43. Wilson MA. NMR Techniques and Applications in Geochemistry and Soil Chemistry. Oxford: Pergamon Press; 1987.

44. Buhl JC and Löns J. Synthesis and crystal structure of nitrate enclathrated sodalite $\mathrm{Na}_{8}\left[\mathrm{AlSiO}_{4}\right]_{6}\left(\mathrm{NO}_{3}\right)_{2}$. Journal of Alloys and Compounds. 1996; 235:41-47. http://dx.doi.org/10.1016/09258388(95)02148-5 
45. Mundus C, Mueller-Warmuth W and Buhl JC. Crystallisation of a basic sodalite under hydrothermal conditions studied by MAS-NMR, XRD and DTA/DTG. EJM European Journal of Mineralogy. 1996; 8:231-239.

46. Covarrubias C, Garcia R, Arriagada R, Yanez J and Garland T. Cr(III) exchange on zeolites obtained from kaolin and natural mordenite. Microporous and Mesoporous Materials. 2006; 88:220-231. http://dx.doi.org/10.1016/j. micromeso.2005.09.007

47. Ocanto F, Acosta N, Linares CF and Urbina de Navarro C. Estudio de la influencia del par anionico $\mathrm{NO}_{3}^{-}-\mathrm{Br}^{-}$en la sintesis del sistema cancrinita-sodialita. Revista Latinoamericana de Metallurgia y Materiales. 2007; 27:106-113.

48. Walton RI, Milange F, O'Hare D, Davies AT, Sankar G and Catlow CRA. An in situ energy dispersive X-ray diffraction study of the hydrothermal crystallization of zeolite A. 1 . Influence of reaction condions and transformation into sodalite.
Journal of Physical Chemistry B. 2001; 105:83-90. http:// dx.doi.org/10.1021/jp002711p

49. Szostak R. Molecular sieves. London: Blackie Academic and Professional; 1998.

50. Ogura M, Kawazu T, Takahashi H and Okubo T. Aluminosilicate species in the hydrogel phase formed during the aging process for the crystallization of FAU zeolite. Chemistry of Materials. 2003; 15:2661-2667. http://dx.doi.org/10.1021/ cm0218209

51. Lee S-R, Han Y-S, Park M, Park G-S and Choy J-H. Nanocrystalline Sodalite from $\mathrm{Al}_{2} \mathrm{O}_{3}$ Pillared Clay by SolidSolid Transformation. Chemistry of Materials. 2003; 15:48414845. http://dx.doi.org/10.1021/cm034614p

52. Fechtelkord M, Posnatzki B and Buhl JC. Synthesis of basic cancrinite in a butanediol-water system. Chemistry of Materials. 2001; 13:1967-1975. http://dx.doi.org/10.1021/ $\mathrm{cm} 001136 \mathrm{z}$ 